\title{
Arginine vasopressin infusion is sufficient to model clinical features of preeclampsia in mice
}

\author{
Jeremy A. Sandgren, ${ }^{1}$ Guorui Deng, ${ }^{1}$ Danny W. Linggonegoro, ${ }^{1}$ Sabrina M. Scroggins, ${ }^{2}$ \\ Katherine J. Perschbacher, ${ }^{1}$ Anand R. Nair, ${ }^{1}$ Taryn E. Nishimura, ${ }^{2}$ Shao Yang Zhang, ${ }^{1}$ Larry N. Agbor, ${ }^{1}$ \\ Jing Wu, ${ }^{1}$ Henry L. Keen, ${ }^{1}$ Meghan C. Naber, ${ }^{1}$ Nicole A. Pearson, ${ }^{1}$ Kathy A. Zimmerman, ${ }^{3}$ \\ Robert M. Weiss, ${ }^{3}$ Noelle C. Bowdler, ${ }^{2}$ Yuriy M. Usachev, ${ }^{1}$ Donna A. Santillan,, ${ }^{2,6}$ \\ Matthew J. Potthoff, ${ }^{1,6,7,8,9}$ Gary L. Pierce, ${ }^{4,6,7}$ Katherine N. Gibson-Corley, ${ }^{5,6,8}$ Curt D. Sigmund, ${ }^{1,6,7,8,9}$ \\ Mark K. Santillan, ${ }^{2,6}$ and Justin L. Grobe ${ }^{1,6,7,8,9}$ \\ 'Department of Pharmacology, ${ }^{2}$ Department of Obstetrics \& Gynecology, ${ }^{3}$ Department of Internal Medicine, ${ }^{4}$ Department \\ of Health \& Human Physiology, ${ }^{5}$ Department of Pathology, ${ }^{6}$ University of lowa Hospitals \& Clinics Center for Hypertension \\ Research, ${ }^{7}$ François M. Abboud Cardiovascular Research Center, ${ }^{8}$ Fraternal Order of Eagles' Diabetes Research Center, and \\ ${ }^{9}$ Obesity Research \& Education Initiative, University of lowa, lowa City, lowa USA.
}

Copeptin, a marker of arginine vasopressin (AVP) secretion, is elevated throughout human pregnancies complicated by preeclampsia (PE), and AVP infusion throughout gestation is sufficient to induce the major phenotypes of PE in mice. Thus, we hypothesized a role for AVP in the pathogenesis of PE. AVP infusion into pregnant C57BL/6] mice resulted in hypertension, renal glomerular endotheliosis, intrauterine growth restriction, decreased placental growth factor (PGF), altered placental morphology, placental oxidative stress, and placental gene expression consistent with human PE. Interestingly, these changes occurred despite a lack of placental hypoxia or elevations in placental fms-like tyrosine kinase-1 (FLT1). Coinfusion of AVP receptor antagonists and time-restricted infusion of AVP uncovered a mid-gestational role for the AVPR1A receptor in the observed renal pathologies, versus mid- and late-gestational roles for the AVPR2 receptor in the blood pressure and fetal phenotypes. These findings demonstrate that AVP is sufficient to initiate phenotypes of PE in the absence of placental hypoxia, and indicate that AVP may mechanistically (independently, and possibly synergistically with hypoxia) contribute to the development of clinical signs of PE in specific subtypes of human PE. Additionally, they identify divergent and gestational time-specific signaling mechanisms that mediate the development of PE phenotypes in response to AVP.

Conflict of interest: MKS, DAS, and JLG have submitted Patent Cooperation Treaty applications (PCT/ US2014/015327, PCT/US2014/015631, and PCT/US2018/027152) and hold a US Patent (no. 9,937,182) describing a role for AVP in the potential diagnosis and therapeutic treatment of preeclampsia. Ongoing research by MKS, DAS, and JLG developing diagnostic tests for preeclampsia that involve measurements of the AVP system are supported in part by a seed grant from Carmentix Pte Ltd/Esco Ventures.

Submitted: December 20, 2017 Accepted: August 17, 2018 Published: October 4, 2018

\section{Reference information:} JCI Insight. 2018;3(19):e99403. https://doi.org/10.1172/jci. insight. 99403.

\section{Introduction}

Preeclampsia $(\mathrm{PE})$ is a common and life-threatening disease of pregnancy characterized by hypertension, proteinuria, renal glomerular endotheliosis (RGE), fetal growth restriction, placental hypoxia, headache, and edema along with various other nonspecific symptoms $(1,2)$. Clinical signs and symptoms of PE typically manifest around mid-gestation no earlier than week 20 , and progress in severity until birth or early fetal and placental delivery. If PE is allowed to progress, maternal seizures, coma, and maternal and fetal death can occur. Fetal and placental delivery remain the only cure.

While the initiating cause of PE is unknown, it is known that women with PE exhibit placental dysfunction early in pregnancy (3). Fetal trophoblasts responsible for invading and dilating maternal spiral arteries that supply blood to the growing fetoplacental unit are dysfunctional in PE (3), and this is thought to lead to abnormally small spiral arteries, poor placental perfusion, and placental and fetal hypoxia.

It is generally accepted that $\mathrm{PE}$ is a heterogeneous disease, as highlighted by the complex clinical diagnostic criteria defining the disease (4). Increasing evidence supports the concept that the variability in clinical presentation of PE is at least in part due to the existence of distinct subtypes of PE. For example, it was reported that gene expression clustering in placental tissue can be used to define multiple unique molecular subtypes of PE (5). Further, a growing number of independent animal models of PE have been developed 
in recent decades involving genetic, surgical, and pharmacological interventions targeting various distinct mechanisms and resulting in partially overlapping development of specific clinical features of PE (6-8). Due to the heterogeneity of clinical symptoms and molecular mechanisms involved in $\mathrm{PE}$, there is currently no single comprehensive animal model that captures all the clinical and molecular features of PE (6-8). To understand the molecular mechanisms of the various subtypes of PE, it is important to continue to develop novel preclinical models of the disease.

In 2014, our group demonstrated that copeptin, a stable biomarker of arginine vasopressin (AVP) secretion (9), is elevated in women with PE as early as the sixth week of gestation (10). While this was the earliest gestational time point examined in any such study, other independent research teams around the globe have now similarly demonstrated elevations in copeptin both before and after the clinical diagnosis of PE using an array of commercially available assays (11-17), supporting the conclusion that AVP secretion is increased early and throughout pregnancies that eventually develop PE. Importantly, we have also demonstrated that infusion of AVP throughout gestation is sufficient to initiate major PE phenotypes in mice, including elevated systolic blood pressure (SBP), proteinuria, RGE, and intrauterine growth restriction (10). Nonetheless, the role of AVP in the pathogenesis of human PE and the mechanism(s) by which AVP leads to PE phenotypes in mice remain unclear.

Therefore, the overall objectives of the current study were to explore the utility of AVP infusion to model the clinical syndrome of $\mathrm{PE}$, and to clarify the receptor- and gestational time-dependent actions of AVP that elicit phenotypes of $\mathrm{PE}$ in mice.

\section{Results}

Model development. Our first objective was to validate and extend the results of our previous initial characterization of the effects of AVP infusion throughout mouse pregnancy (10). Most importantly, we discovered that significant variation exists in the quality and quantity of AVP supplied between lots of AVP offered both within, and between, individual commercial vendors. Initial animal studies performed using distinct lots of AVP from multiple vendors resulted in variable induction of PE phenotypes in mice, which correlated with the quality and quantity of AVP supplied (data not shown). Therefore, careful analytical analyses, including mass-spectrometric confirmation of both the quantity and purity of AVP supplied, was required for every vial of AVP used for these studies (data not shown). Throughout the studies described below, Sigma-Aldrich AVP (catalog V9879), lot 025M4856V and 126M4842V were utilized. Sigma-Aldrich lot SLBF6741V and Phoenix Peptides (catalog 065-07) lot 432419 were specifically avoided. AVP was infused at $24 \mathrm{ng} / \mathrm{hr}$ into the subcutaneous space of the flank via osmotic minipump; this dosing schedule was selected based on a preliminary dose-response evaluation in which 0.24 and $2.4 \mathrm{ng} / \mathrm{hr}$ infusion rates had no discernable effects, while $240 \mathrm{ng} /$ hr caused excessive fetoplacental death and resorption and/or prevented pregnancy (Supplemental Figure 1; supplemental material available online with this article; https://doi.org/10.1172/jci.insight.99403DS1). Subcutaneous infusion of AVP at $24 \mathrm{ng} / \mathrm{hr}$ resulted in a $47 \%$ increase in plasma AVP in AVP-infused dams compared with saline-infused dams (at gestational day 12.5 [GD 12.5], pregnant with saline infusion: $n=5,33.7 \pm$ 5.1 , vs. pregnant with AVP infusion: $n=5,49.8 \pm 6.0 \mathrm{pg} / \mathrm{ml}, 1$-tailed $t$ test $P=0.04$ ). Although nonpregnant human plasma AVP concentrations are typically lower, endogenous AVP is elevated to this level in mice, rats, and humans in both pregnant and nonpregnant states in response to various distinct challenges (18-20).

Blood pressure. To characterize the cardiovascular phenotypes of the AVP-infusion model of PE, we first examined blood pressure (BP) using radiotelemetric transducers. Compared with prepregnancy baseline, mice chronically infused with saline $(0.11 \mu \mathrm{l} / \mathrm{hr}$, s.c.) exhibited no changes in SBP (Figure $1, \mathrm{~A}$ and E), diastolic BP (DBP) (Figure 1, B and F), pulse pressure (PP) (Figure 1, C and G), or heart rate (HR) (Figure $1, \mathrm{D}$ and $\mathrm{H}$ ) during the third week of gestation (GD 13.5-17.5). In contrast, mice chronically infused with AVP (24 ng/hr, s.c.) exhibited robust elevations in SBP and PP, with no changes in DBP or HR. Importantly, infusion of AVP in nonpregnant female C57BL/6J mice did not alter SBP, urine volume, or urine protein concentration (Supplemental Figure 2).

Vascular function. These data led us to hypothesize that infusion of AVP leads to vascular dysfunction and altered uterine and placental blood flow, as has been documented in PE pregnancies $(21,22)$ and in various models of the disease (23-27). Toward that end, we measured endpoints of arterial stiffness and resistance via pulse wave velocity (PWV) and Doppler ultrasonography during GD 10.5-13.5 in mice. Aortic PWV (Figure 2A), a measure of arterial stiffness, did not change with AVP infusion. Measures of uterine artery function, including peak systolic velocity (PSV) (Figure 2B), end diastolic velocity (EDV) (Figure 2C), or resistive 


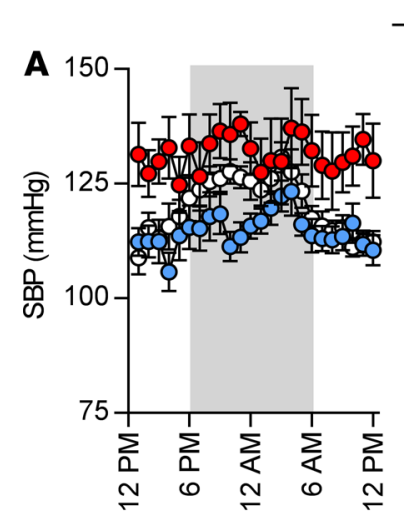

E

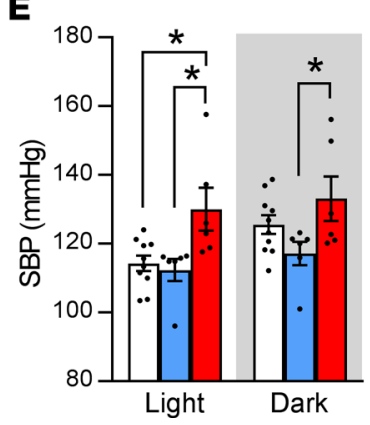

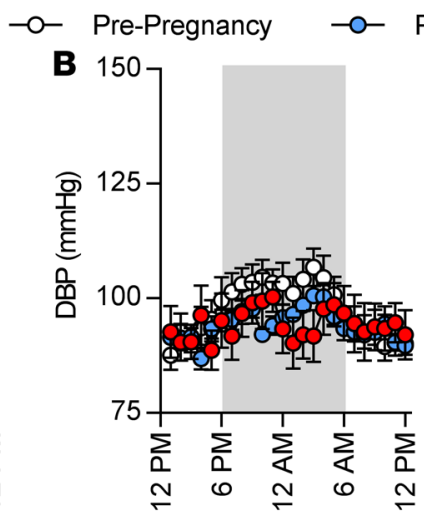

$\mathbf{F}$

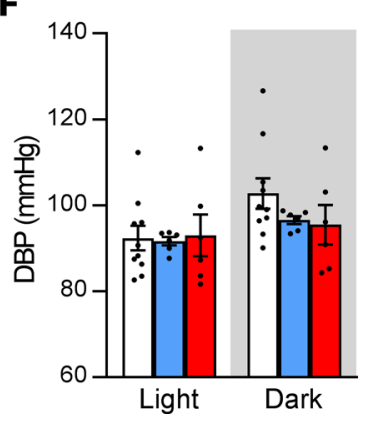

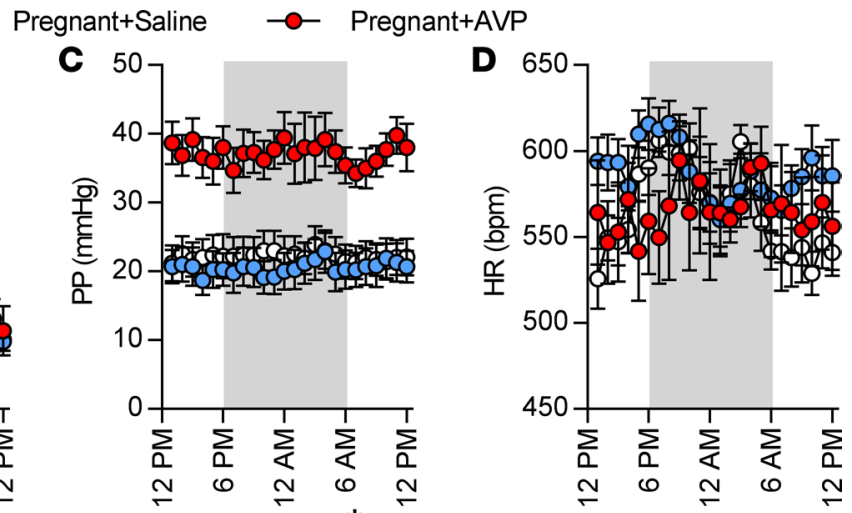

$\mathbf{G}$

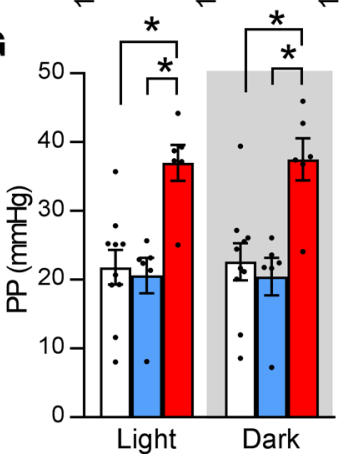

$\mathbf{H}$

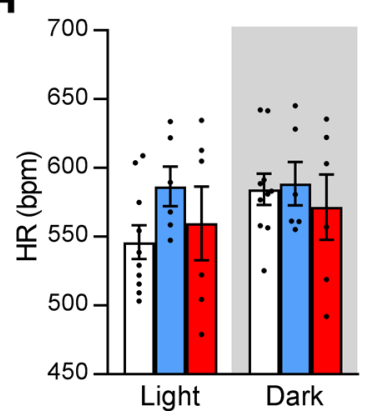

Figure 1. Gestational arginine vasopressin (AVP) infusion causes an isolated systolic hypertension. Effects of pregnancy and AVP on (A and E) systolic blood pressure (SBP), (B and $\mathbf{F}$ ) diastolic blood pressure (DBP), (C and $\mathbf{G})$ pulse pressure (PP), and ( $\mathbf{D}$ and $\mathbf{H})$ heart rate (HR). Analyses by 2-way ANOVA with repeated measures and Tukey's test for multiple comparisons. Data are expressed as the mean \pm SEM. ${ }^{*} P<0.05$. Baseline $n=10$, saline $n=6$, AVP $n=6$.

index (RI) (Figure 2D) were similarly unaffected by AVP infusion. In addition to uterine artery dysfunction, defects in umbilical artery flow have also been associated with adverse pregnancy outcomes (28-31). Specifically, multiple groups have demonstrated associations between decreased umbilical PSV and PE (32, 33), with others demonstrating associations between decreased, absent, or even reversed diastolic umbilical velocity and increased RI with uteroplacental insufficiency seen in PE $(34,35)$. In pregnant mice receiving AVP infusion, umbilical artery PSV (Figure 2E) was decreased and EDV (Figure 2F) and RI (Figure 2G) were unchanged.

Placental development. Interestingly, ultrasonography detected a significant decrease in placental thickness in mice receiving AVP infusion (Figure $2 \mathrm{H}$ ). Therefore, we examined placental morphology at GD 12.5. According to Carnegie-stage comparisons (36), this time in mouse development approximately corresponds to day 40 of human embryologic development when many of the early mechanistic changes in $\mathrm{PE}$ are observed, and GD 12.5 has also been used previously to examine placental morphology in mouse models of PE (27). AVP-infused mice in this cohort exhibited early- and mid-gestational elevations in SBP ( $\triangle$ SBP from prepregnancy baseline: saline: $-7.6 \pm 3.1$, vs. AVP: $+3.5 \pm 2.2 \mathrm{mmHg}, P=0.01$ ) and spot urine protein concentration (saline: $27.1 \pm 2.7$, vs. AVP: $44.1 \pm 2.5 \mathrm{mg} / \mathrm{ml}, P<0.01$ ). Placental layer thicknesses of the decidua and junctional zone at GD 12.5 were not changed by AVP, but the labyrinth layer, which contains fetus-derived capillaries, was smaller (Figure 3A). Spiral artery diameter (Figure 3B) and number per section (Figure 3C) were both decreased by AVP. Representative images of histological measurements are shown in Supplemental Figure 3.

Placental mechanisms. PE is typically characterized by poor spiral artery remodeling (37-40), possibly due to reductions in the angiogenic factor placental growth factor (PGF) (41-43) and increases in its inhibitor, fms-like tyrosine kinase-1 (FLT1) (44). Although PGF was decreased by AVP infusion (Figure 3D), placental FLT1 was also significantly downregulated by AVP infusion (Figure 3E). mRNA levels also appeared to decrease for both genes (Pgf. saline $n=18,1.0$ [0.7- to 1.3-fold] vs. Avp $n=21,0.3$-fold [0.2- to 0.4-fold] [ \pm 1 SEM], $P<0.05$; total Flt1: saline $n=18,1.0$ [0.9- to 1.2 -fold] vs. $A v p n=21,0.5$-fold [0.4- to 0.7-fold] [ $\pm 1 \mathrm{SEM}], P=0.06$ ).

Given the association of spiral artery morphology and decreased PGF with placental hypoxia (45-48), we hypothesized that infusion of AVP would lead to placental hypoxia, despite overall normal uterine artery velocity and resistance. We first examined the subcellular localization of hypoxia-inducible factor-1 $\alpha$ 
A
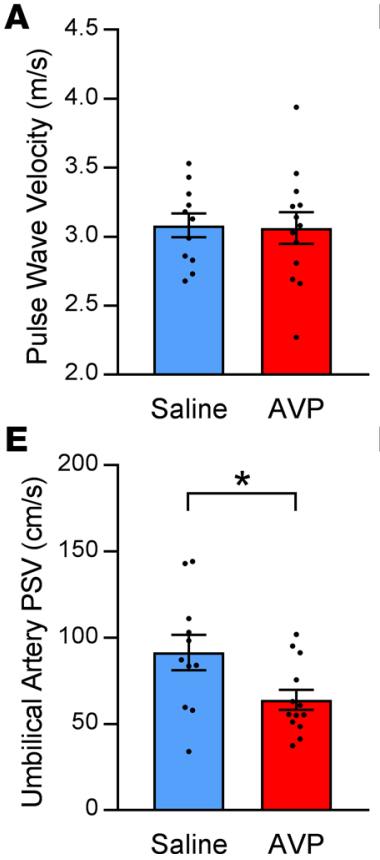

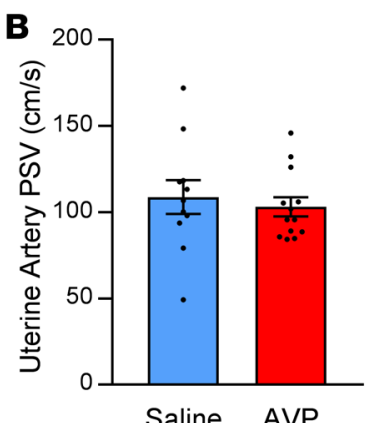

$\mathbf{F}$

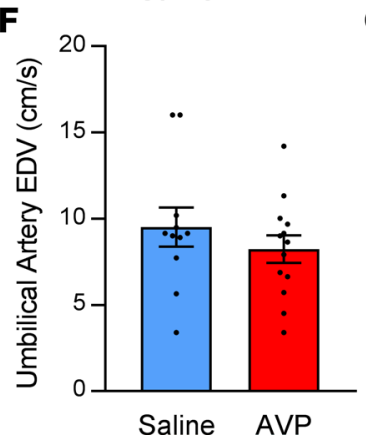

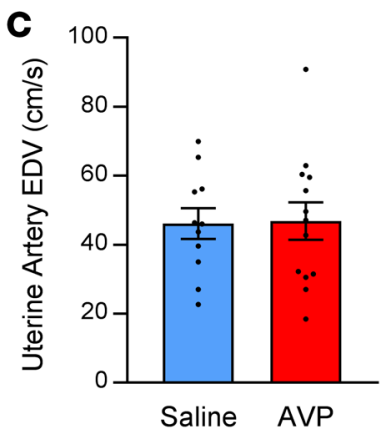

G

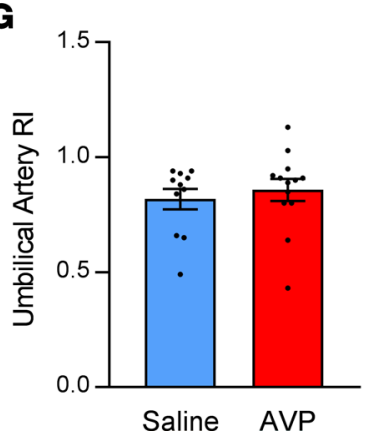

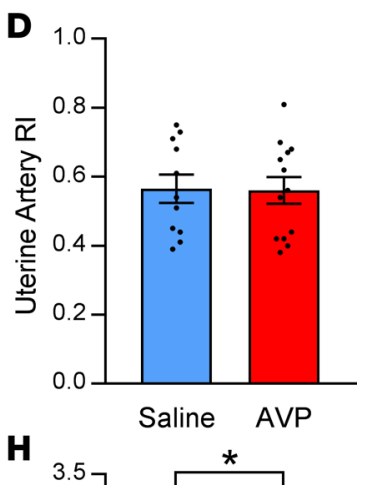

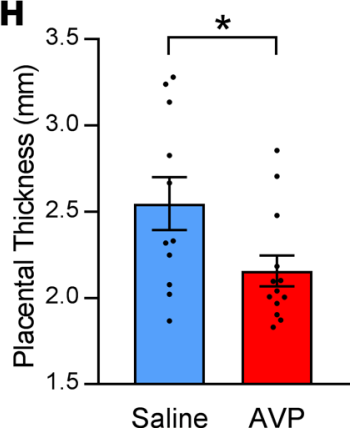

Figure 2. Arginine vasopressin (AVP) has minor or no effect on blood flow velocity and resistance in uterine or umbilical arteries. Effects of AVP on (A) aortic pulse wave velocity (PWV) as well as uterine artery (B) peak systolic velocity (PSV), (C) end diastolic velocity (EDV), and (D) resistive index (RI). Umbilical artery (E) PSV, (F) EDV, and (G) RI. (H) Fetal placental thickness by Doppler ultrasonography. Analyses by Student's $t$ test. Data are expressed as the mean \pm SEM. ${ }^{*} P<0.05$. Saline $n=11$, AVP $n=13$.

(HIF1A), an important transcription factor that translocates to the nucleus and binds to DNA to initiate transcription in the absence of oxygen, in placental tissue at GD 12.5. We found no differences in HIF1A concentrations within soluble nuclear or chromatin-bound subcellular fractions between placentas from saline- and AVP-infused mouse pregnancies (Figure 3F). In addition, transcriptional markers of HIF1A activity were also unchanged or decreased by AVP at GD 12.5 or 17.5 (Supplemental Figure 4). Similarly, at GD 12.5 AVP had no effect on maximal invasion depth of cytokeratin-8-immunopositive cytotrophoblasts migrating into the decidual layer (Supplemental Figure 5), a process that has previously been demonstrated to be stimulated by local hypoxia (49-51).

Placental gene expression. To explore whether AVP affected gene expression and pathways implicated in $\mathrm{PE}$, we performed RNA sequencing (RNA-Seq) on placentas from mice treated with saline or AVP. First, gene set enrichment analysis (GSEA) was performed to further explore whether AVP infusion resulted in placental hypoxia. Supporting our above results, we found no evidence of placental hypoxia using 2 independent hypoxia signatures (Table 1 and Figure 4A) (52). Subsequent GSEA of publicly available microarray data from human placentas compiled by Leavey et al. (GSE75010) (53) revealed that chronically hypertensive women with superimposed $\mathrm{PE}$ also did not exhibit enrichment for markers of placental hypoxia (Table 1), supporting the concept that placental hypoxia is variable across subtypes of human PE. Interestingly, despite the lack of enrichment for markers of hypoxia in the placentas from mice infused with AVP, GSEA found significant enrichment for markers of oxidative stress in the placentas (FDR $q$ value $=0.05$, family-wise error rate $[\mathrm{FWER}] P$ value $=0.02$, normalized enrichment score $[\mathrm{NES}]=1.39$ ) (Figure 4B).

Next, using differential gene expression analysis, we identified 87 differentially expressed transcripts corresponding to 82 unique genes as well as 3 noncoding RNAs (Figure 4C). Of note, many of these genes were already implicated in human $\mathrm{PE}$, as determined either by comparing against multiple previously published gene expression studies of human placental tissues from pregnancies complicated by preeclampsia (Figure 4D), and as determined by performing manual literature searches against the 82 genes that were differentially expressed in response to AVP treatment. Of the 82 differentially expressed genes (DEGs) reviewed manually, all but one exhibited directional changes similar to those documented in human PE (Table 2). That gene, NFAT5, is known to be elevated by hypoxia as well as during hyperosmolality (54), neither of which are detected in the AVP infusion model (Table 1 and Supplemental Figure 6, respectively). 

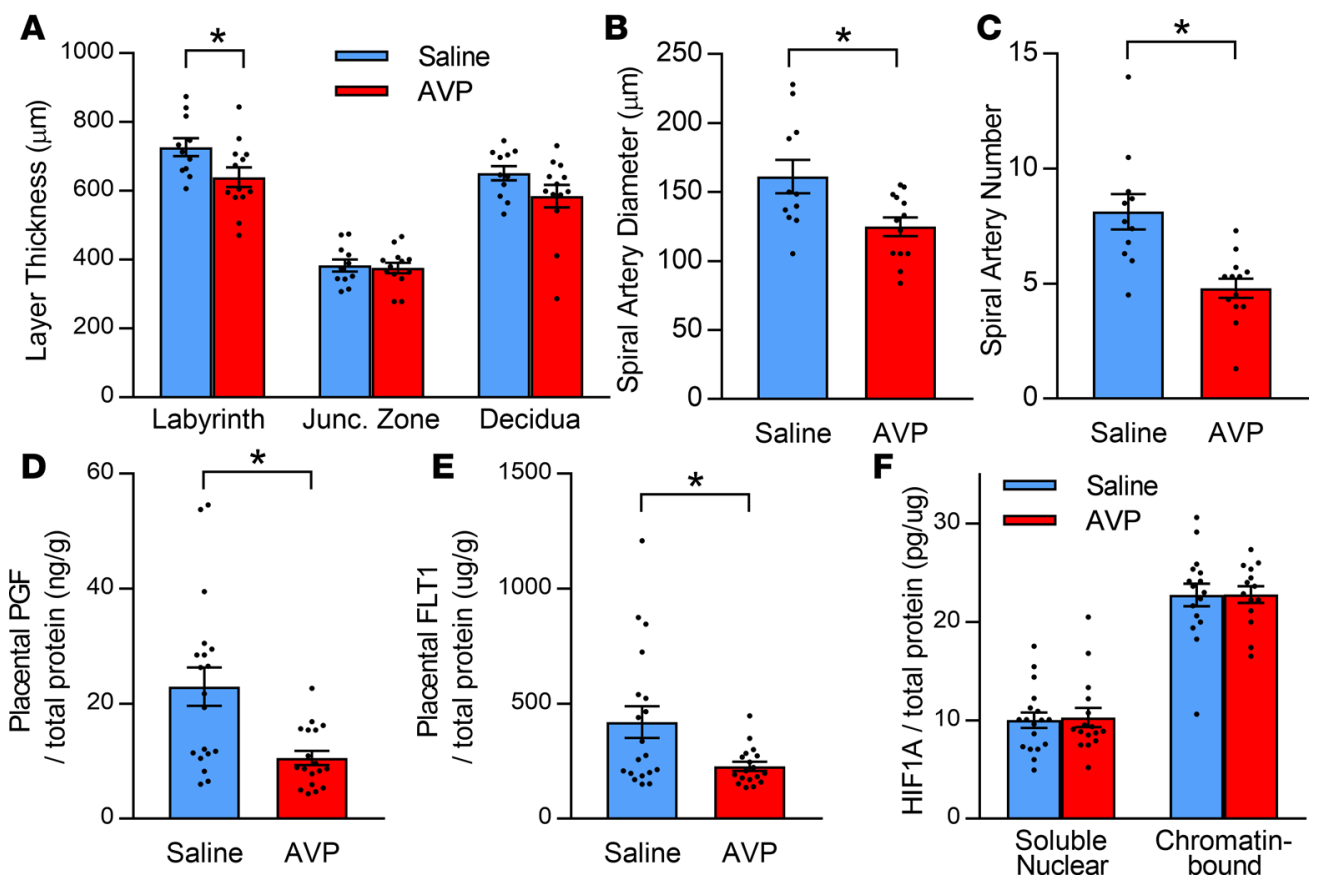

Figure 3. Arginine vasopressin (AVP) alters placental morphology and angiogenesis at gestational day 12.5. (A) Effects of AVP on thickness of placental labyrinth, junctional zone, and decidua (saline $n=11$, AVP $n=13$ ). Measures of angiogenesis, including (B) spiral artery diameter and (C) spiral artery number (saline $n=11$, AVP $n=13$ ), as well as angiogenic markers placental (D) PGF and (E) FLT1 (saline $n=20$, AVP $n=20$ ). (F) HIF1A cellular localization in fractionated placentas collected from mice receiving saline or AVP (saline nuclear $n=18$, chromatin $n=16$; AVP nuclear $n=16$, chromatin $n=14$ ). Analyses by Student's $t$ test. Data are expressed as the mean \pm SEM. ${ }^{*} P<0.05$.

We also utilized Ingenuity Pathway Analysis (IPA) to identify molecular pathways that are modified in the GD 12.5 placenta by infusion of AVP (Table 3). We found that signatures for interleukin-2 (IL-2) signaling and calcium signaling, each of which have been implicated in PE (55-57), were both significantly enriched in placentas from AVP-infused pregnancies (Table 3). IPA also identified methylglyoxal pathways $(58,59)$, base excision repair mechanisms (60-67), and mevalonate pathways (68), which have also been associated with PE. Further, IPA revealed that the disease and functional annotations that were significantly enriched in placentas from AVP-infused pregnancies included hypertension, preeclampsia, as well as cell death (Supplemental Table 1). Finally, IPA identified upstream mediators that are expected to cause effects on the transcriptome similar to those observed with AVP infusion. As expected, this list

Table 1. Enrichment for hypoxia signatures in RNA from GD 12.5 placentas of C57BL/6] mice infused with AVP (24 ng/hr) or saline, and placentas from human pregnancies reported in GSE75010

\begin{tabular}{|c|c|c|c|c|c|c|}
\hline \multirow[b]{2}{*}{ Subgroup } & \multirow[b]{2}{*}{ Control } & \multirow[b]{2}{*}{ AVP or PE } & \multicolumn{2}{|c|}{ GRD Hypoxia Score } & \multicolumn{2}{|c|}{ Harris Hypoxia Score (52) } \\
\hline & & & NES (PE vs. Con) & FDR q value & NES (PE vs. Con) & FDR q value \\
\hline \multicolumn{7}{|l|}{ Mouse } \\
\hline AVP-infusion & 4 & 6 & 0.79 & 0.69 & 0.93 & 0.36 \\
\hline \multicolumn{7}{|l|}{ Human } \\
\hline \multicolumn{7}{|l|}{$\begin{array}{l}\text { No Chronic } \\
\text { Hypertension }\end{array}$} \\
\hline Preterm & 12 & 19 & 1.71 & 0.01 & 1.57 & $<0.01$ \\
\hline Term & 18 & 6 & 1.73 & 0.02 & 1.63 & 0.02 \\
\hline \multicolumn{7}{|l|}{$\begin{array}{l}\text { With Chronic } \\
\text { Hypertension }\end{array}$} \\
\hline Preterm & 10 & 11 & 1.17 & 0.31 & 0.96 & 0.54 \\
\hline Term & 10 & 3 & 1.05 & 0.43 & 1.11 & 0.30 \\
\hline
\end{tabular}


A Hypoxia-Associated Genes
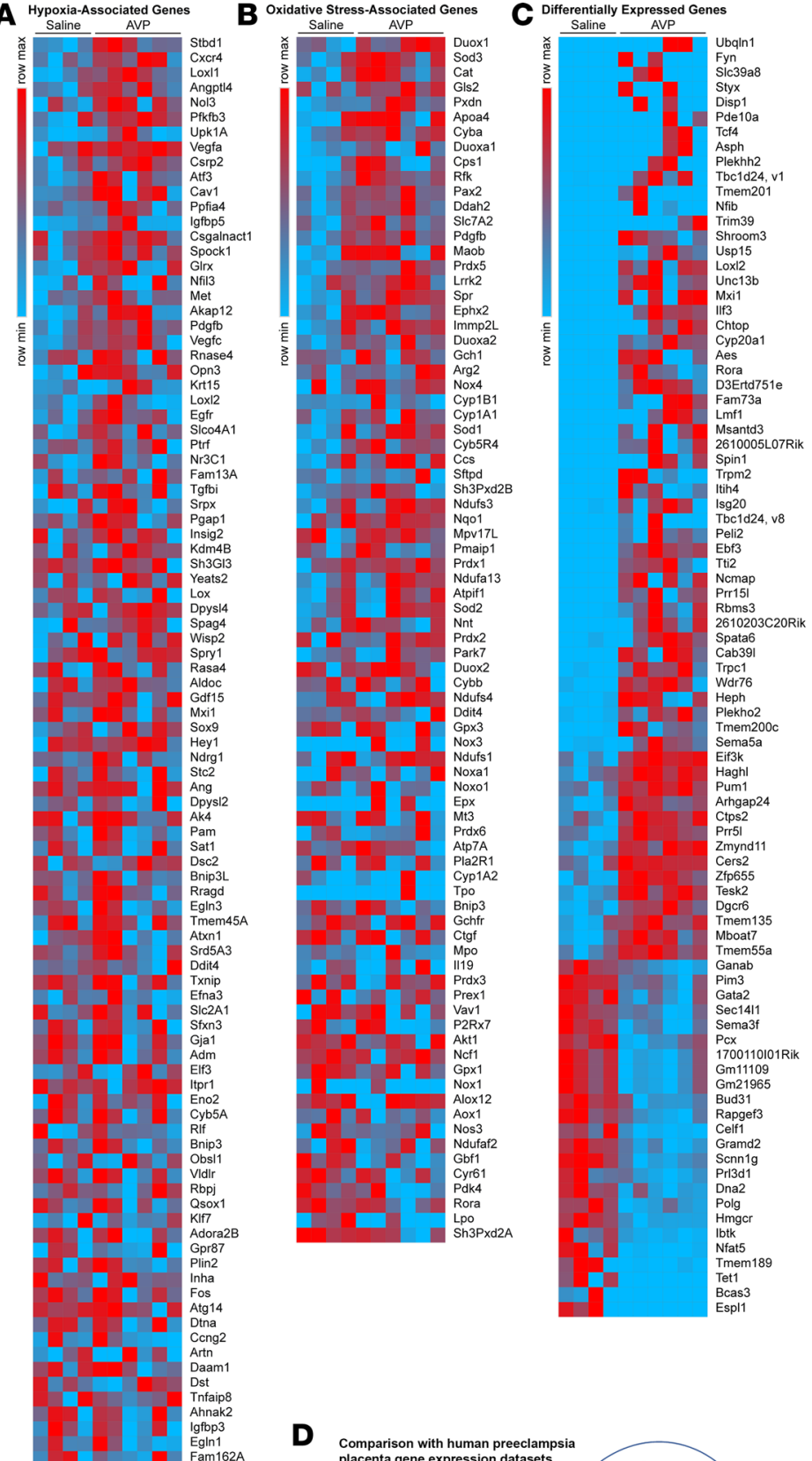

Comparison with human preeclampsia placenta gene expression datasets

Egln1
Fam162A
$S 100 A^{2}$

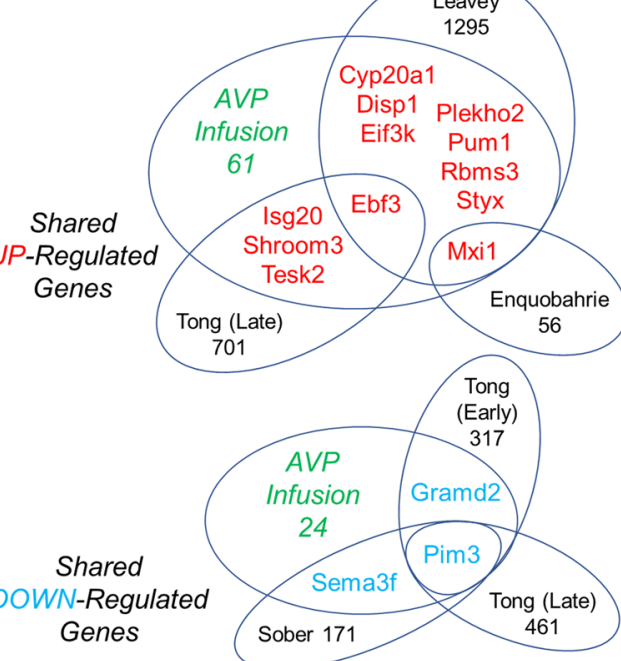

Figure 4. Gene expression profiling of placentas from dams infused with saline $(n=4)$ or arginine vasopressin (AVP) $(n=6)$ dams. (A) Heatmap illustrating relative expression of genes associated with hypoxia (GRD Hypoxia gene set). (B) Heatmap illustrating relative expression of genes associated with oxidative stress (M15990 gene set). (C) Heatmap illustrating relative expression of 87 differentially expressed genes identified by DESeq2 (FDR < 0.1). (D) Venn diagrams illustrating up- and downregulated genes in AVP-infused mouse placenta (AVP Infusion) that are similarly changed in human placenta in pregnancies complicated by preeclampsia, as described in the text. Numbers indicate total number of genes significantly changed as noted in individual data sets (Leavey [ref. 5], early- or late-onset preeclampsia subsets by Tong [ref. 102], Enquobahrie [ref. 103], and Sober [ref. 103]), whereas genes noted in shared spaces of Venn diagrams are shared by at least 2 overlapping data sets.

included AVP and desmopressin (an AVPR2 receptor agonist) (Supplemental Table 2). It also identified calcium as a potential upstream mediator.

Next, to determine whether AVP could act directly upon the placenta, we measured expression of AVP receptors and other mediators in human and mouse placentas. Through in silico reanalysis of GSE75010, we confirmed that genes for AVP receptors AVPR1A, AVPR1B, AVPR2, cullin-5 (CUL5), and the oxytocin receptor (OXTR), to which AVP can bind and activate, are all present in human placentas (Figure 5A). We also confirmed that $A V P$, oxytocin (OXT), and LNPEP, the enzyme that degrades AVP, are expressed by human placentas (Figure 5A). Of these, AVP, AVPR1A, and OXTR were increased in pregnancies affected by $\mathrm{PE}$, demonstrating dysregulated local AVP synthesis and signaling in PE (Figure 5B). In mouse placenta, the various AVP receptors, Oxt, and Lnpep were also expressed (Figure 5C), but none were modified by AVP infusion (Figure 5D). This may indicate that increases in human placental AVP system gene expression during PE are secondary to other stimuli such as genetics, epigenetics, hypoxia, or other mechanisms. HTR8/SVneo cells, an immortalized cell line derived from first-trimester, extravillous invasive human placental trophoblasts (69), also express $A V P$, AVPR1A, AVPR2, CUL5, and OXTR (Figure 5E). Importantly, a dose-dependent increase in intracellular $\mathrm{Ca}^{2+}$ concentration $\left(\left[\mathrm{Ca}^{2+}\right]_{\mathrm{i}}\right)$ was observed in response to AVP (Figure $\left.5 \mathrm{~F}\right)\left(\mathrm{EC}_{50}=\right.$ $440 \pm 200 \mathrm{nmol} / \mathrm{l})$, demonstrating that AVP can directly activate intracellular calcium signaling cascades in trophoblasts.

Receptor and time dependency of AVP action: BP. We next examined how AVP infusion leads to PE phenotypes by clarifying the role(s) of various AVP receptors and the times of gestation they are activated during pregnancy. To do so, we performed pharmacological studies to block specific AVP receptors as outlined in Figure 6A. Briefly, we infused saline or AVP with or without the AVP receptor antagonists, conivaptan (nonselective AVPR1A and AVPR2 antagonist), relcovaptan (AVPR1A antagonist), and tolvaptan (AVPR2 antagonist) through GD 17.5. In other treatment groups, we infused AVP only through GD 2.5 or GD 9.5 to determine whether AVP action early in pregnancy is sufficient to initiate the development of PE phenotypes. Mice infused with 
Table 2. Differentially expressed RNA transcripts within AVP-treated GD 12.5 placenta that have previously been experimentally associated with human PE

\begin{tabular}{|c|c|c|c|}
\hline Transcript & AVP model & Human PE & References \\
\hline Trpm2 & $\uparrow$ & $\begin{array}{l}\text { Increased in maternal urine at } 20 \text { weeks. Increased in maternal plasma in first and second trimesters } \\
\text { and also maternal serum at term, most strongly in cases with IUGR; Protein evident in syncytiotrophoblasts } \\
\text { and villous endothelial cells and also increased in PE placenta }\end{array}$ & $(105-110)$ \\
\hline Itih4 & $\uparrow$ & Evaluated within a panel of predictive biomarkers within maternal serum & (111) \\
\hline Nemap & $\uparrow$ & Increased in microarray analysis of PE placenta & (112) \\
\hline Sema3f & $\downarrow$ & $\begin{array}{l}\text { Reduced in PE placenta, maternal serum, amniotic fluid, and cord blood at delivery; Correlates with fetal } \\
\text { and placental masses; At } 16-18 \text { weeks, reduced in amniotic fluid and predictive of PE (AUC }=0.941)\end{array}$ & (113) \\
\hline Nfat5 & $\downarrow$ & $\begin{array}{l}\text { Increased in hypoxic human PE placenta, in animal models of hypoxic PE, } \\
\text { and immortalized trophoblasts with hypoxic or hyperosmotic stimuli }\end{array}$ & $(54,115,116)$ \\
\hline
\end{tabular}

saline exhibited a mid-gestational decrease in SBP that returned to baseline levels at the end of pregnancy. In contrast, SBPs of mice infused with AVP failed to decrease in mid-gestation and then increased above baseline at the end of gestation (Figure 6B). Chronic coadministration of the nonspecific AVPR1A+AVPR2 receptor antagonist, conivaptan, completely prevented AVP-induced changes in SBP. However, coadministration of the selective AVPR1A antagonist, relcovaptan, had no effect on SBP in AVP-infused mice. Interestingly, coadministration of the selective AVPR2 antagonist, tolvaptan, also had no effect on SBP in AVP-infused mice in mid-gestation, but completely ameliorated the SBP elevations in late-gestation. Although SBP was elevated in mice solely infused with tolvaptan in late-gestation, chronic infusion of receptor antagonists in the absence of exogenous AVP infusion had no major effect (Supplemental Figure 7). Collectively, these findings support the concept that AVP elevates SBP in pregnancy through a combination of AVPR1A+AVPR2 receptor activation in early- and mid-gestation and AVPR2-specific activation in late-gestation.

To further examine the gestational time-dependent effects of AVP on SBP, we examined the consequences of only infusing AVP during specific phases of gestation. Whereas infusion of AVP throughout pregnancy (to GD 17.5) resulted in both a failure to reduce SBP in mid-gestation and an elevation in SBP in late-gestation, infusion of AVP only up to GD 2.5 had no effect on SBP at any examined time point (Figure 6C). Interestingly, infusion of AVP only through GD 9.5 resulted in a failure to reduce SBP in midgestation (similar to AVP infusion throughout pregnancy), but SBP returned to match that of saline-infused controls by late-gestation. These findings support the idea that SBP is increased by AVP throughout gestation and that the continued action of AVP is required to maintain increases in SBP.

Receptor and time dependency of AVP action: Renal function. To characterize the receptor- and time-dependent effects of AVP on renal and fetal phenotypes, we measured urine protein, assessed glomerular damage by electron microscopy, and measured fetal weight near the end of gestation (GD 17.5). As previously demonstrated, GD 17.5 urine protein concentration was elevated by AVP infusion throughout pregnancy (Figure 7A). Unexpectedly, given the established dipsogenic effect of AVP in the nonpregnant state (70),

Table 3. Canonical pathways changed by AVP infusion

Ingenuity Canonical Pathways

Methylglyoxal Degradation I

Calcium Signaling

Regulation of IL-2 Expression in Activated and Anergic T Lymphocytes

Base Excision Repair (BER) pathway

Mevalonate Pathway I

Superpathway of Inositol Phosphate Compounds
$P$ value
0.010
0.026
0.032
0.042
0.045
0.050 

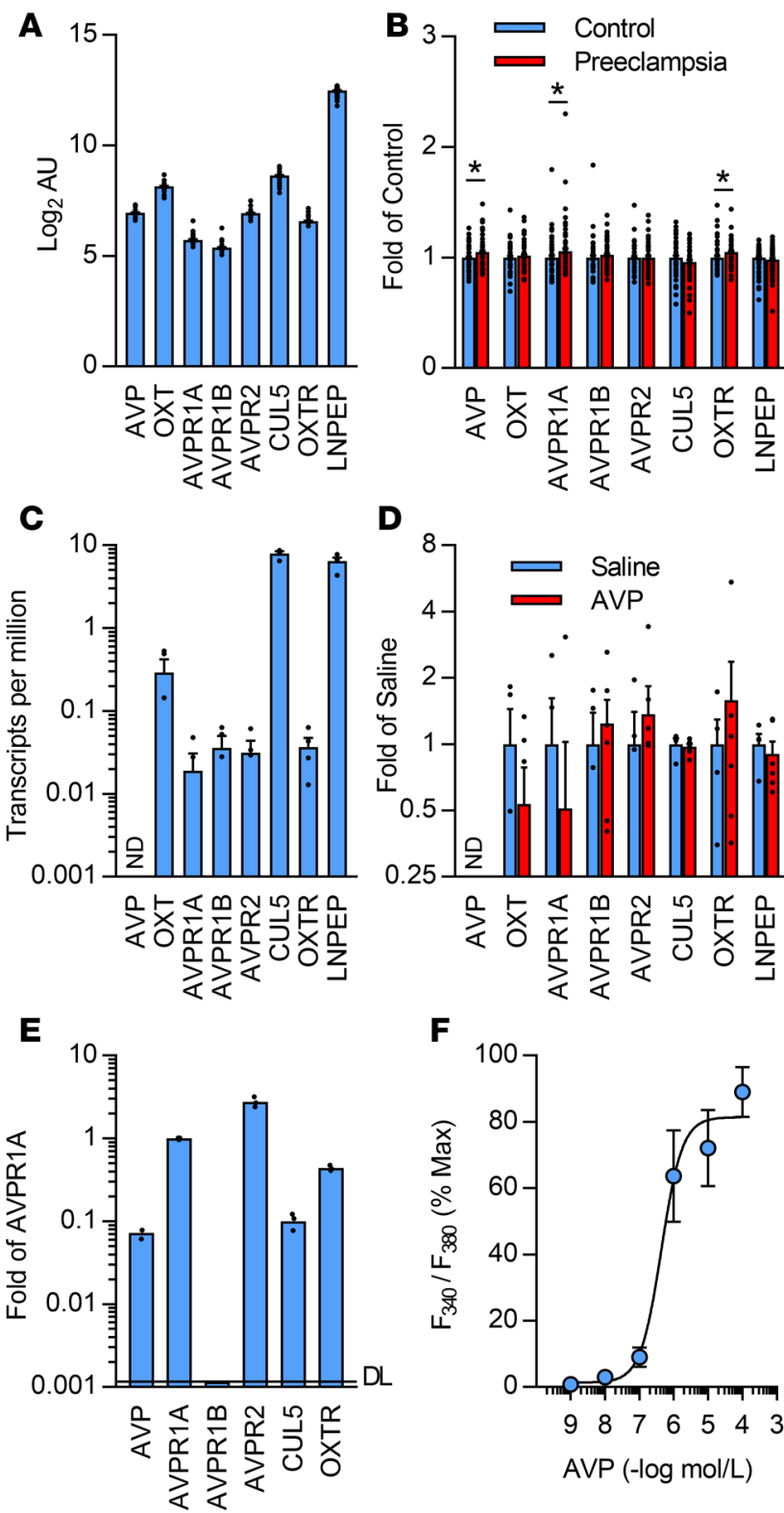

.

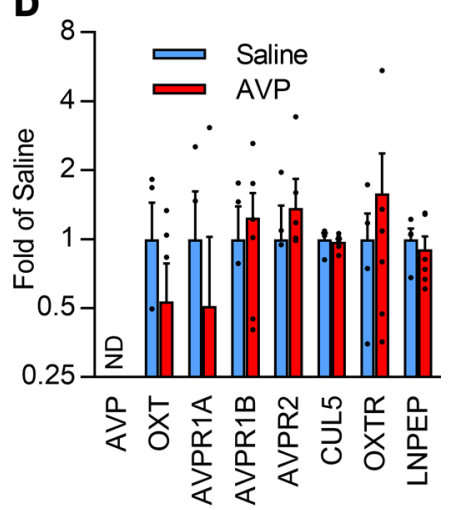

$\mathbf{F}$

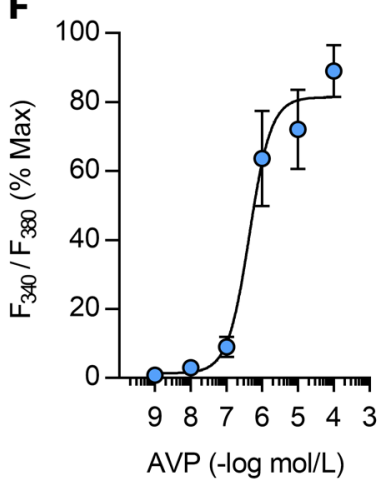

Figure 5. Components of arginine vasopressin (AVP) system are present in placentas and trophoblasts. (A) AVPsystem components are present in human placentas. (B) Relative abundance of AVP-system components in preeclampsia compared with control pregnancies (control $n=77$, preeclampsia $n=80$, GSE75010). (C) Presence of AVP-system components in mouse placenta and (D) response of those components to AVP (saline $n=4$, AVP $n=6)$. (E) Presence of AVP-system components in HTR8 human placental trophoblasts and (F) intracellular $\mathrm{Ca}^{2+}$ response of HTR8 cells to AVP ( $n=4$ distinct passages) Increases in intracellular $\mathrm{Ca}^{2+}$ concentration $\left(F_{340} / F_{380}\right)$ were evoked by application of increasing concentrations of AVP. For each sample, $F_{340} / F_{380}$ responses for each cell were normalized to the amplitude of maximal AVP concentration. Analyses by Student's $t$ test. Data are expressed as the mean \pm SEM. ${ }^{*} P<0.05$.

this dose of AVP significantly reduced water intake (Supplemental Figure 8A) without affecting urine volume (Supplemental Figure $8 \mathrm{~B}$ ). Elevations in urine protein concentration were completely prevented by relcovaptan but not tolvaptan, demonstrating an important role for AVPR1A in this phenotype. Relcovaptan also prevented increases in 24-hour urine protein caused by AVP (Figure 7B). Urine protein effects of conivaptan were not interpretable, as conivaptan independently caused renal damage (Supplemental Figure 8, C and E). In the absence of AVP, relcovaptan and tolvaptan had no effect on urine protein or glomerular morphology (Supplemental Figure 8, C-E). Interestingly, AVP infusion through GD 9.5 but not 2.5 was sufficient to elevate urine protein at GD 17.5 (Figure 7A), although there were no differences in 24-hour urine protein (Figure 7B). Finally, blood was collected via submandibular lance into tubes coated with lithium-heparin from a subset of GD 17.5 dams to examine common markers of renal function. AVP infusion had no significant effect on major electrolytes, glucose, or markers of renal function, as determined by a handheld clinical chemistry analyzer (iSTAT) (Supplemental Table 3).

Receptor and time dependency of AVP action: Fetal development. AVP infusion led to decreases in fetal weight that were prevented by tolvaptan (Figure 7C). Low fetal weight appears to be dependent on lategestation AVP action, as infusion of AVP only through GD 2.5 or 9.5 had no effect on fetal weight. Interestingly, although AVP alone had no effect on placental mass, tolvaptan coinfusion reduced placental 

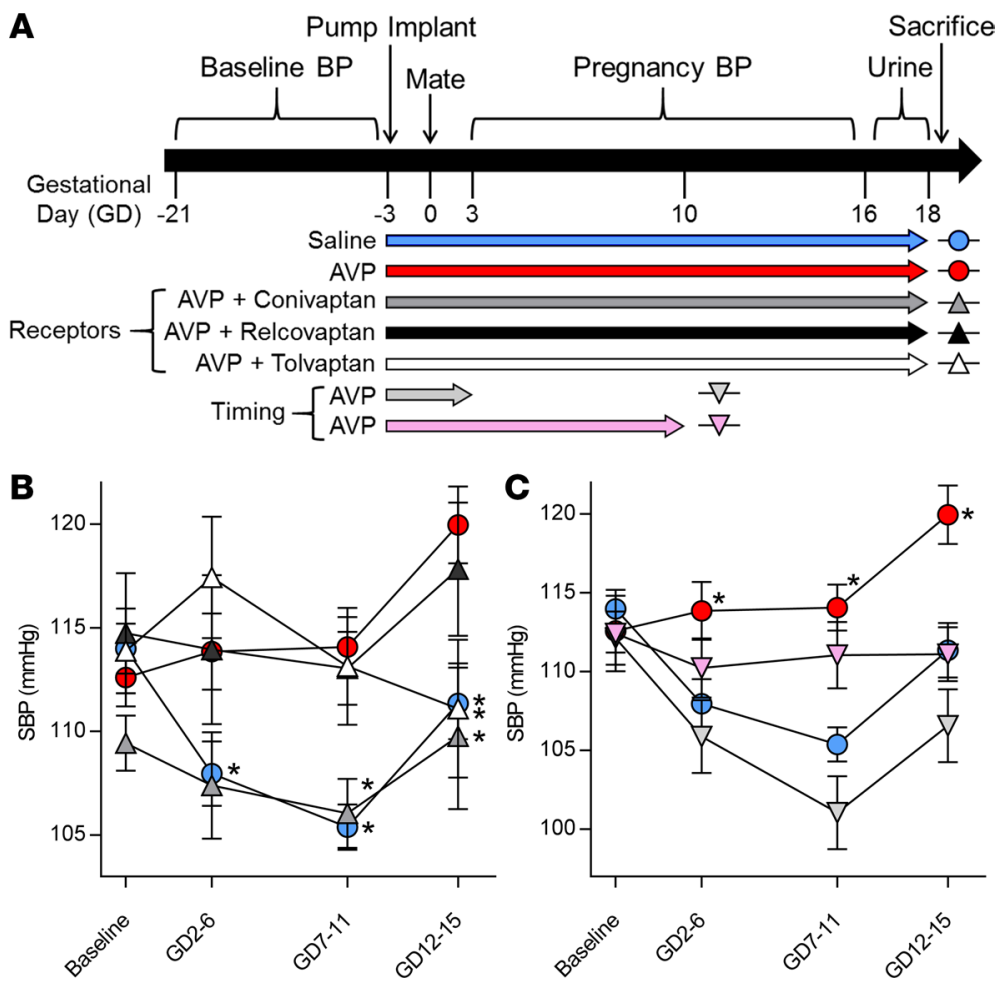

Figure 6. Experimental design, and blood pressure effects of arginine vasopressin (AVP) and AVP-antagonist coinfusion. Our experimental design is shown in A and described in the text. (B) Effects of saline $(n=40), \operatorname{AVP}(n=27)$, AVP + conivaptan $(n=11)$, AVP + relcovaptan $(n=9)$, and AVP + tolvaptan $(n=11)$ throughout pregnancy. Analyses by 3-way ANOVA followed by Tukey's test for multiple comparisons. ${ }^{*} P<0.05$ versus saline. (C) AVP infusion through only GD 2.5 $(n=18)$ and GD $9.5(n=12)$. Saline and AVP shown again for clarity. Analyses by 3-way ANOVA followed by Tukey's test for multiple comparisons. Data are expressed as the mean $\pm \mathrm{SEM}$. ${ }^{*} P<0.05$ versus AVP.

mass compared with all other treatment groups (Figure 7D). Tolvaptan therefore significantly reduced the fetal/placental mass ratio when coinfused with AVP throughout gestation (Figure 7E).

Receptor and time dependency of AVP action: Renal structure. RGE, a pathognomonic histological observation for PE characterized by endothelial swelling in maternal glomeruli, was again observed in mice receiving AVP throughout pregnancy (Figure 7F), similar to our previous report (10), when glomeruli were examined at high magnification by electron microscopy. Interestingly, mice coinfused with AVP and relcovaptan had no detectable glomerular damage, whereas mice coinfused with AVP and tolvaptan exhibited a modest protection of glomerular structure. Additionally, AVP infusion through GD 2.5 or 9.5 was not sufficient to induce RGE, indicating that the action of AVPR1A (and to a lesser degree, AVPR2) late in pregnancy is required for RGE in this model. Unfortunately, nonspecific combined antagonism of both AVPR1A and AVPR2 was again uninterpretable, as conivaptan itself without AVP coadministration caused renal ultrastructural damage (Supplemental Figure 8E). Major structural changes to the glomeruli were not as obviously evident when examined using hematoxylin and eosin (H\&E) staining and light microscopic, low-magnification imaging methods (Supplemental Figure 9).

Hepatic complications. Finally, AVP is known to act through its AVPR1A receptor to modulate protein catabolism, lipid metabolism, bile acid synthesis, and glucose homeostasis through actions at the liver (71-73), and thus we tested the possibility that excess AVP may contribute to hepatic dysfunction during pregnancy, observed during complications such as HELLP syndrome. No differences were observed in ALT or AST activities between plasmas from saline- or AVP-infused dams on GD 17.5 (Supplemental Figure 10), leading us to conclude that the $24 \mathrm{ng} / \mathrm{hr}$, s.c. dosing schedule of AVP is insufficient to model hepatic complications and the HELLP syndrome.

Summary. These data, along with findings we recently reported regarding the effect of the $24 \mathrm{ng} / \mathrm{hr}$ infusion of AVP upon the immune system (74), are summarized in Figure 8A. Further, our interpretation of the gestational time-dependent involvement of various AVP receptors in the development and maintenance of 

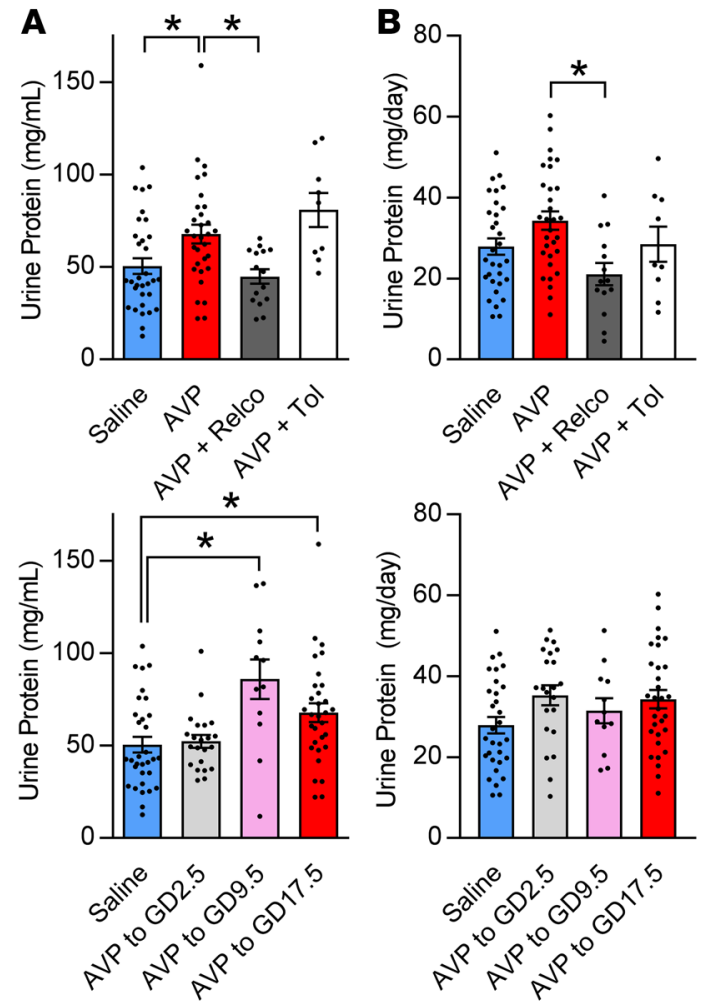
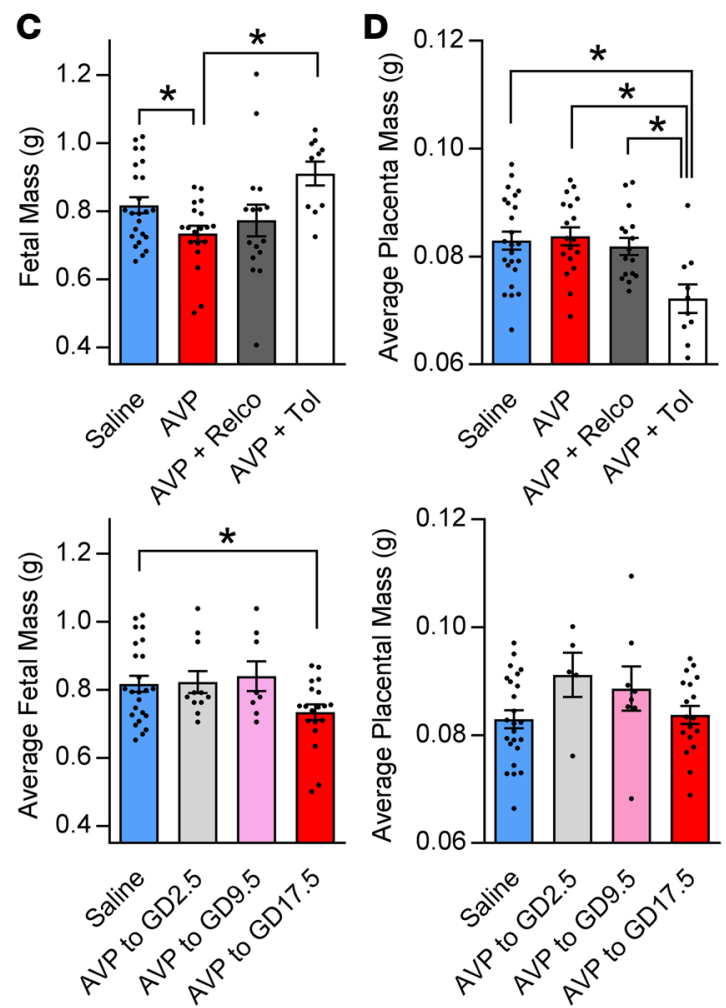
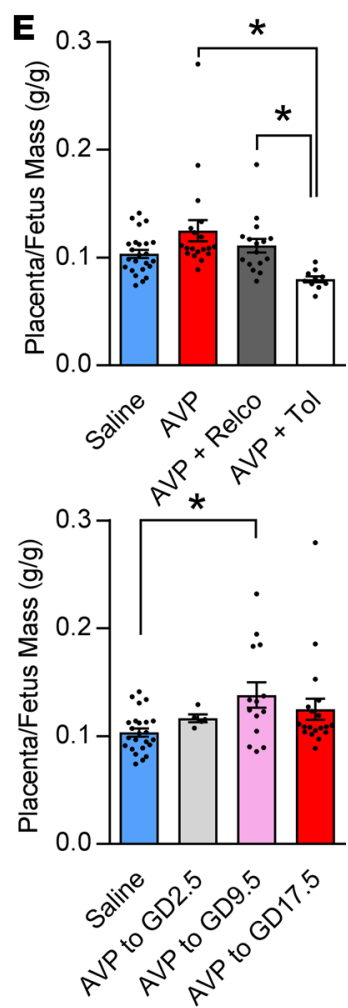
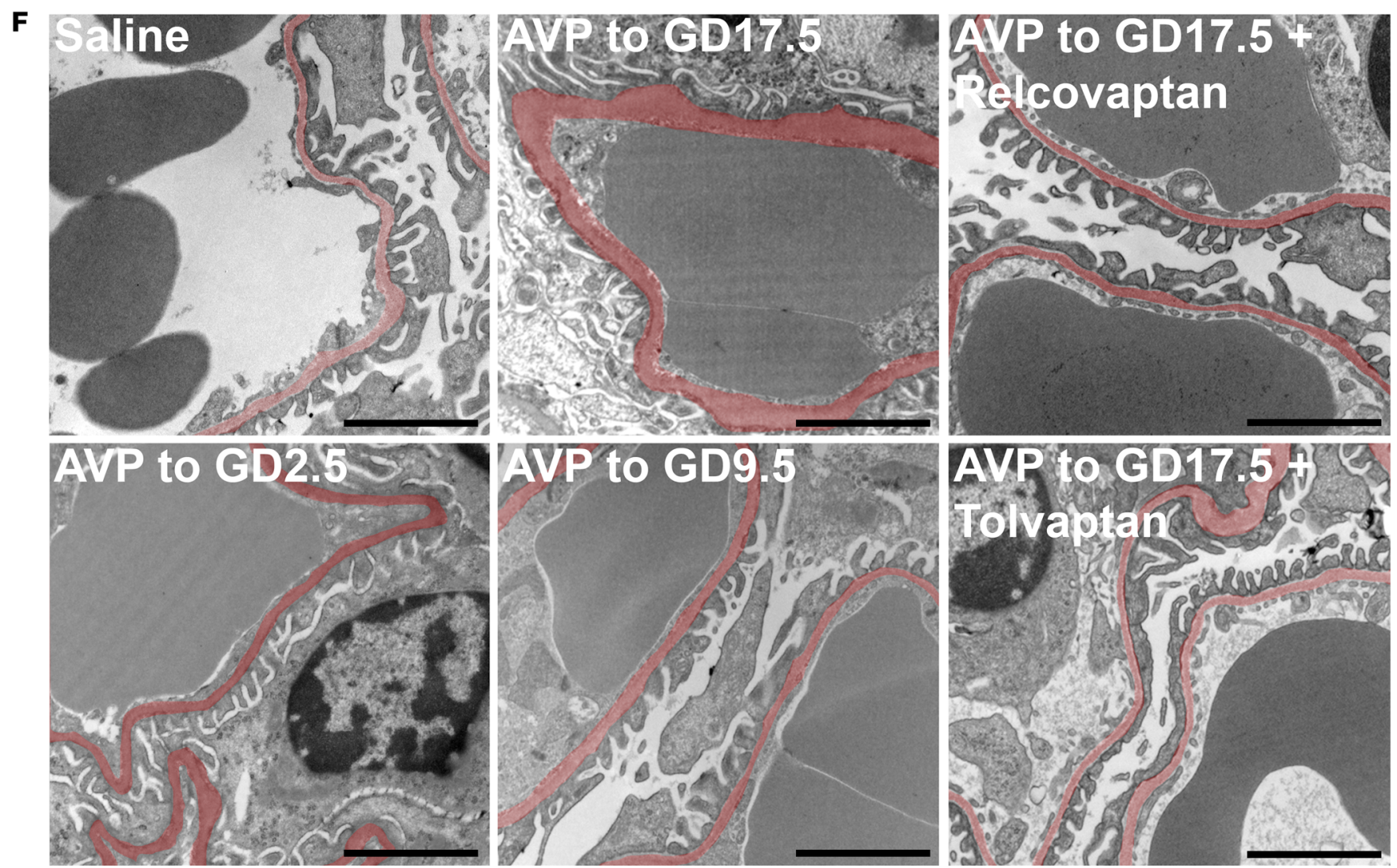

Figure 7. Renal and fetal effects of arginine vasopressin (AVP) and AVP-antagonist coinfusion. (A) Effects of saline $(n=32)$, AVP $(n=30)$, AVP + relcovaptan ( $n$ $=15)$, AVP + tolvaptan ( $n=9)$, and AVP to GD $2.5(n=22)$ and GD $9.5(n=12)$ on urine protein concentration. (B) Twenty-four-hour urine protein, (C) fetal mass, (D) placental mass, and (E) placenta/fetal mass ratio effects of saline $(n=24)$, AVP $(n=19)$, and receptor combinations (same $n$ 's as panel A). For panels A-E, saline and AVP-treated mice are reported twice for clarity. (F) RGE with AVP, as indicated by the thickened and distorted glomerular basement membrane (pink) that was prevented by relcovaptan ( $n=3$ for all groups). Scale bars: $2 \mu \mathrm{m}$. Analyses for receptor inhibitor studies by 2-way ANOVA with Dunnett's multiple-comparisons procedure, compared with AVP. For timing studies, analyses by 1-way ANOVA and Dunnett's multiple-comparisons procedure, compared with saline. Data are expressed as the mean \pm SEM. ${ }^{*} P<0.05$. 


\begin{tabular}{cccc}
\hline A & Phenotype & $\begin{array}{c}\text { Human } \\
\text { Preeclampsia }\end{array}$ & $\begin{array}{c}\text { AVP infusion in } \\
\text { pregnant mice }\end{array}$ \\
\hline $\begin{array}{c}\text { Maternal } \\
\text { Hemodynamics }\end{array}$ & Maternal AVP secretion $\uparrow$ & Yes & (infused) \\
& Gestational hypertension & Yes & Yes \\
& Renal Glomerular Endotheliosis & Yes & Yes \\
& Proteinuria & Yes & Maybe / Mild \\
\hline Placenta & $\downarrow$ Uterine Artery Flow & Yes & No \\
Development & Spiral Artery Malformation & Yes & Yes \\
and Function & Placental Hypoxia & Yes & No \\
& Placental FLT1 $\downarrow$ & Yes & No \\
\hline Fetal Effect & Placental PIGF $\downarrow$ & Yes & Yes \\
Immune & Placental Oxidative Stress & Yes & Yes \\
System & Fetal Growth Restriction & Yes & Yes \\
Balance & Th1 activation & Yes & Yes \\
\hline
\end{tabular}

B

\begin{tabular}{rrr} 
& \multicolumn{2}{c}{ Gestational Timeline } \\
\cline { 3 - 3 } Elevated Blood Pressure & $\mathrm{V}_{2 \mathrm{~A}}+\mathrm{V}_{2}$ activation & \\
Urine Protein & $\mathrm{V}_{1 \mathrm{~A}}$ activation \\
Renal Glomerular Endotheliosis & & $\mathrm{V}_{1 \mathrm{~A}}+\mathrm{V}_{2}$ activation \\
Intrauterine Growth Restriction & $\mathrm{V}_{2}$ activation
\end{tabular}

Figure 8. Summary and working model. (A) Table summarizing major phenotypes of human preeclampsia, and the sufficiency of the AVP infusion (24 ng/hr, s.c.) in pregnant wild-type [57BL/6) mice to phenocopy each, as evaluated in the current manuscript plus our recent publications $(10,104)$. (B) Working model, based on data presented herein, illustrating the relative involvement of AVPR1A and AVPR2 receptors at various stages of gestation, in the development of blood pressure, renal, and fetal phenotypes in the AVP infusion model.

major clinical features of PE are graphically depicted in Figure 8B. Elevations in SBP and PP appear to be mediated by AVPR1A and AVPR2 in early- to mid-gestation, and this shifts to only AVPR2 in late gestation. Urine protein concentration seems to be increased by mid-gestational AVPR1A activation, while RGE requires both AVPR1A and AVPR2 activation near the end of gestation. Finally, fetal growth restriction appears to be driven primarily by late-pregnancy AVPR2 activation.

\section{Discussion}

AVP secretion, as measured by plasma copeptin, has now been shown by multiple groups around the world to be elevated in the first trimester and throughout gestation in PE (10-17). While it is difficult to directly test the hypothesis that AVP can cause human PE, insights gained from studies of obstetric outcomes in subjects with AVP-associated disorders support a potential association between elevated AVP secretion and PE. For example, Nawathe and Govind recently reviewed cases of syndrome of inappropriate antidiuretic hormone (SIADH) during pregnancy and found that 13 of 18 reported cases developed PE (75). In addition, other disorders associated with elevated AVP secretion, such as diabetes mellitus (76), obesity (77), and hypertension (78) are all established risk factors for PE. These findings support an association between AVP and PE and prompt studies to test a causal role for AVP in the development of PE. Here we show that low-dose infusion of AVP in mice is sufficient to cause the physiological phenotypes of PE, including hypertension, RGE, and intrauterine growth restriction (IUGR), and also induces many of the cellular and molecular phenotypes of PE, including decreased placental PGF, placental oxidative stress, and decreased spiral artery number and diameter. Additionally, we documented a complex participation of AVPR1A and AVPR2 receptors at specific time points throughout gestation in the development of physiological phenotypes of PE in this model.

Despite observing decreases in spiral artery diameter as well as number and the known effects of AVP on the vasculature in the nonpregnant state (79-81), we were surprised that AVP did not induce placental hypoxia or changes in uterine artery velocity or resistance. Placental hypoxia has long been associated with PE (82) and is an essential etiology for multiple models of the disease (6-8). However, recent studies by Leavey et al. have identified populations of patients with PE that do not exhibit molecular signatures consistent with hypoxia (5). Acknowledging the relatively small sample size 
included, reanalysis of the GSE75010 data set similarly supports differential enrichment of markers for hypoxia in subsets of humans with $\mathrm{PE}$, such as those with or without chronic hypertension before pregnancy (Table 1). Therefore, there appears to be heterogeneity in the development of placental hypoxia during $\mathrm{PE}$, indicating that additional complementary mechanisms must also contribute to the pathogenesis of $\mathrm{PE}$.

Thus, our data support the conclusion that AVP is sufficient, independently from hypoxia-mediated mechanisms, to induce clinical phenotypes of PE. This conclusion, along with the observations that most pregnancies complicated by $\mathrm{PE}$ are characterized by both some degree of placental hypoxia and elevated secretion of AVP, supports the concept that AVP and hypoxia represent dissociable mechanisms that may independently and/or synergistically contribute to the pathogenesis of human PE. These data and concepts fit well within the current understanding of the molecular mechanisms of PE, specifically that aspects thought to be important in the pathogenesis of $\mathrm{PE}$, such as proinflammatory and dysangiogenic mechanisms, are independent of hypoxia (83-85). In addition, hypoxia markers like HIF1A can be induced in placental cells under normoxic conditions via inflammatory pathways (86) in the absence of hypoxia. Clinically, the existence of at least 2 major, independently contributing mechanisms may therefore help explain the heterogeneity of symptom development in human PE.

The lack of evidence for the induction of placental hypoxia by chronic AVP infusion during pregnancy in mice indicates that this manipulation does not fully model typical human PE. On average, human PE is characterized by placental hypoxia, but that observation does not preclude the existence of individual $\mathrm{PE}$ patients who do not exhibit placental hypoxia. It is important to appreciate that both in the current study (Supplemental Figure 2) and in our previous study (10), chronic low-dose (24 ng/ hr, s.c.) infusion of AVP into nonpregnant female mice did not cause hypertension; this effect is only unmasked in the context of pregnancy. Thus, whether AVP infusion represents a comprehensive model of a subtype of human PE or a partial model of all types of PE (when performed in the context of placental hypoxia) requires further investigation, though the utility of the AVP infusion intervention to model pregnancy-related hypertensive disease and its sequelae remains.

The determination that both AVPR1A and AVPR2 have nonoverlapping, complementary, and timedissociable actions to mediate the development of $\mathrm{PE}$ phenotypes in mice implies that treatment regimens targeting patients with AVP-induced PE symptoms would need to antagonize combinations of both AVPR1A and AVPR2 throughout gestation. While other AVP receptors, such as AVPR1B, may play a role in the development of PE phenotypes, the robust prevention of PE phenotypes in mice by AVPR1A and AVPR2 antagonists supports only minor roles for these alternative receptors. This finding may support relcovaptan and tolvaptan as novel preventative agents against AVP-mediated subtype(s) of PE. However, the effects of these antagonists in human pregnancies and whether phenotype reversal (rather than prevention, as in our studies) is possible are important questions that need to be answered before definitive clinical trials could be initiated.

Instead of therapeutically targeting AVPR1A and AVPR2, it may be simpler and more direct to target synthesis or release of AVP. It is known that AVP secretion increases early in normal pregnancy, but the mechanisms behind this process are not clear and may be modified in PE (19). Future studies aimed at understanding the mechanism(s) of exaggerated AVP secretion during human PE may therefore lead to the discovery of earlier and even more robust biomarkers, and also better inform AVP-centric treatment approaches. In particular, the development of conditional (i.e., floxed) alleles for each of the AVP receptors is required to permit tissue-specific, complete disruption of individual receptors to implicate specific receptor and tissue targets in the development of individual phenotypes. For example, such methods are required to selectively disrupt AVP receptors in individual cell types of the placenta to probe the role of these receptors in the development of PE phenotypes in response to AVP infusion. Such studies can be directed based on insights gained by the pharmacological approaches utilized in the current study.

In summary, we have determined that infusion of AVP throughout mouse pregnancy is sufficient to initiate many of the major phenotypes of PE. Phenotype development is mediated through synergistic activation of multiple AVP receptors at various stages throughout gestation, can be prevented by AVP antagonists, and is independent from placental hypoxia. These data support the concept that interference with AVP secretion or action may provide a therapeutic approach in patients with PE. 


\section{Methods}

Animal subjects. Experiments were conducted in 10- to 20-week-old female C57BL/6J mice obtained from the Jackson Laboratories. Animals were maintained in conventional housing, including a standard 12-hour lightdark cycle and an ambient temperature of $25^{\circ} \mathrm{C}$, with ad libitum access to tap water and chow (Teklad, 7013).

$B P$ by radiotelemetry. BP was recorded by telemetric probe as previously described (87-91). Radiotelemetric probes (DSI, model TA11PA-C10), were implanted into the common carotid artery under $2 \%$ isoflurane anesthesia and animals were allowed to recover for at least 1 week before recording.

Pregnancy studies. Baseline BPs were recorded via tail-cuff plethysmography as previously described (10). Mice were individually placed in restraint tubes and warmed to promote tail blood flow. Mice were acclimated for 10 days before 5 days of baseline measurements, which were averaged within subject for a final baseline SBP measurement. Mice were balanced between groups based on SBP, implanted with a micro-osmotic pump, and allowed to recover for 3 days before mating. Males were put in female cages for 1 night and $\mathrm{BP}$ recordings by tail-cuff resumed on GD 2.5. On GD 15.5, mice were transferred to metabolic cages for 48 hours for two 24-hour urine collections and then sacrificed on GD 17.5 for tissue and plasma collection.

Drug preparation and infusion. AVP (24 ng/hr, Sigma-Aldrich, V9879), conivaptan (Vaprisol, $22 \mathrm{ng} / \mathrm{hr}$, Baxter Healthcare), relcovaptan (22 ng/hr, SR 49059) (Sigma-Aldrich, S5701), and tolvaptan (22 ng/hr, Sigma-Aldrich, T7455) were kept at $-20^{\circ} \mathrm{C}$ until reconstituted. AVP and tolvaptan were reconstituted and aliquoted in saline, while relcovaptan was reconstituted and aliquoted in saline with $10 \%$ DMSO. Reconstituted drugs were kept at $-80^{\circ} \mathrm{C}$ until use. Dose of conivaptan was determined by dose-response studies (data not shown) and relcovaptan and tolvaptan doses were calculated to correspond to the $K_{i}$ of conivaptan at AVPR1A and AVPR2, respectively. Micro-osmotic pumps (Alzet model 1004) were filled with corresponding drug for appropriate infusion rate per manufacturer instructions and implanted 3 days prior to mating to allow for surgical recovery. For mice receiving AVP plus an antagonist, 2 pumps were placed, one containing AVP and the other containing antagonist, on opposite flanks. For studies infusing AVP only through GD 2.5 or GD 9.5, micro-osmotic pumps were used that only infused AVP for 1 week (Alzet model 1007D) or 2 weeks (Alzet model 1002), respectively.

PWV measurement. PWV was measured in mice between GD 13 and 19 using Doppler ultrasound (MouseDoppler, Indus Instruments) as previously described $(92,93)$. Mice were placed in a supine position under $2 \%$ isoflurane $/ 1 \%$ oxygen anesthesia and continuous ECG recordings were collected from the paws. A $20-\mathrm{MHz}$ probe was used to image at the descending aorta and, simultaneously, at the abdominal aorta 1 $\mathrm{mm}$ above the exit to the left renal artery. Arrival and transit times were calculated over 5-7 cardiac cycles. The distance between the probes was measured using a caliper. Distance between probes $(\mathrm{m})$ divided by transit time (s) gave PWV (m/s).

Doppler ultrasonography. Abdominal ultrasounds were performed on GD 11-14 by a single blinded investigator. Immediately prior to ultrasound, mice were sedated with midazolam $0.1 \mathrm{mg}$ by s.c. injection. The anterior thorax and abdomen were shaved. The animal was grasped gently by the nape of the neck and cradled in the left lateral recumbent position in the imager's hand. Warmed gel was applied to the ultrasound probe to improve the acoustic interface. Uterine and fetal sonography was performed using a 40-MHz linear array probe coupled to a Vevo 2100R imaging system (VisualSonics), generating approximately 180-200 two-dimensional (2-D) frames per second. Fetal cardiac activity and maternal uterine and umbilical artery flow velocity were visualized using 2-D images and color Doppler. Pulse-wave Doppler evaluation was used to measure flow velocity in the umbilical arteries, and in small branches of the uterine arteries adjacent to the gestational sacs. Resistive index was calculated as $1-(1 /$ pulsatility index), with pulsatility index defined as peak systolic divided by end diastolic velocity by Doppler. All imaging and image analyses were performed by expert technicians blinded to treatment groups (KAZ and NCB).

AVP measurement. Mice at GD 12.5 were sacrificed by live decapitation and collected blood was placed in EDTA tubes before being quickly aliquoted into tubes containing aprotinin ( 0.6 trypsin inhibitory units per $1 \mathrm{ml}$ blood) according to protocol (Phoenix Pharmaceuticals, RK-APRO). After 30 minutes on ice, tubes were centrifuged at $4^{\circ} \mathrm{C}$ at $5,000 \mathrm{~g}$ for 10 minutes and supernatant collected.

Plasma was then extracted by reverse-phase column. Briefly, we combined $100 \mu 1$ of 2 similarly treated plasma samples and diluted the combined plasma with an equal volume of $8 \%$ acetic acid. This was then loaded onto a C18 Sep-Pak cartridge ( $1 \mathrm{ml}, 50 \mathrm{mg}$; Waters) that had been primed with $3 \mathrm{ml}$ methanol followed by $3 \mathrm{ml}$ deionized water using a vacuum manifold. After plasma sample was loaded, the cartridge was washed with $3 \mathrm{ml} \mathrm{4 \%}$ acetic acid and peptides were eluted with $2 \mathrm{ml}$ of a 3:1 acetonitrile/4\% acetic acid solution. 
Extract was frozen overnight and then dried with a SpeedVac (Savant Instruments). Extract was reconstituted in RIA diluent and AVP measured in samples by radioimmunoassay (Phoenix Pharmaceuticals, RK-065-07).

Placental histology. Morphology of the placenta was assessed using methods similar to those reported by Monk, et al. (94). Briefly, mice were euthanized by $\mathrm{CO}_{2}$ asphyxiation and fetoplacental units fixed within the uterus via immersion in $10 \%$ neutral buffered formalin (NBF). Fixed tissues were grossly sectioned in half to see all layers of the placenta followed by routine processing and embedding. Tissues were sectioned at $5 \mu \mathrm{m}$ thickness, and routinely stained with H\&E. Placental morphology was evaluated using an Olympus BX51 with attached microscope camera (Olympus DP71) and Olympus CellSens software. Placental layer thicknesses were determined on 2 separate yet adjacent 5 - $\mu$ m-thick tissue sections. Four to 7 fetoplacental units per dam, and 4 to 6 dams per group were analyzed. The same tool was utilized to measure the widest diameter of the spiral arteries on the same slides. The number of spiral arteries within the decidual layer was manually counted on low magnification $(\times 2)$ throughout the entire section of placenta. All slides were evaluated by a board-certified veterinary pathologist (KNGC) blinded to treatment conditions.

Cell culture and $\left[\mathrm{Ca}^{2+}\right]_{i}$ single-cell imaging. HTR8/SVneo (HTR8) cells, purchased from ATCC (CRL-3271) $(69,95)$, were cultured in RPMI medium supplemented with $10 \% \mathrm{FBS}$ and $1 \%$ penicillin/streptomycin. Cells were grown in standard growth conditions at $37^{\circ} \mathrm{C}$ and $5 \% \mathrm{CO}_{2}$ and were plated on poly-D-lysine-coated (Sigma-Aldrich, P6407) glass cover slides 48 hours prior to the beginning of the experiment. On the day of experiment, cells were loaded with the ratiometric $\mathrm{Ca}^{2+}$ indicator dye Fura-2/AM $(2 \mu \mathrm{M})$ for 25 minutes. Cells were then placed in a flow-through perfusion chamber mounted on an inverted IX-71 microscope (Olympus) and perfused with standard extracellular HEPES-buffered Hanks' salt solution (HH buffer) prior to stimulation with AVP. Fura-2 fluorescence was alternately excited at 340 and $380 \mathrm{~nm}$ (12-mm bandpass) using the Polychrome V monochromator (TILL Photonics) and a $\times 20$ objective (NA 0.75 ; Olympus). Emitted fluorescence was collected at $510 \mathrm{~nm}$ (84-nm bandpass) using an IMAGO CCD camera (TILL Photonics) as previously described (96). The fluorescence ratio $\left(\mathrm{R}=\mathrm{F}_{340} / \mathrm{F}_{380}\right)$ was used as an index of $\left[\mathrm{Ca}^{2+}\right]_{\mathrm{i}}$.

Renal ultrastructure. Kidneys were collected on GD 17.5 and placed in glutaraldehyde solution. Electron microscopic analysis of maternal kidneys was performed at the University of Iowa Department of Pathology using a JEOL JEM-1011 transmission electron microscope and images were interpreted by a boardcertified veterinary pathologist (KNGC) blinded to treatment conditions.

HIF1A localization. Placentas from mice receiving saline or AVP throughout pregnancy were collected on GD 17.5 and underwent subcellular fractionation per kit protocol (Thermo Fisher Scientific, 87790). HIF1A was subsequently detected by ELISA (LifeSpan Biosciences).

Plasma osmolality. Osmolality was measured using a Fiske 2400 Multi-sample Osmometer. Plasma was collected as described above, but in the absence of aprotinin.

Real-timequantitative PCR. RNA from placentas of pregnant GD 12.5 mice were isolated using a mirVana RNA isolation kit (Thermo Fisher Scientific, AM1560) per manufacturer's instructions. Quality assessment and RNA concentration was determined using a Nanodrop Spectrophotometer 2000. Quantitative real-time PCR assays were performed using TaqMan Gene Expression Assays (Thermo Fisher Scientific) or SYBR Green (IDT) primer sets. TaqMan primers: $18 S$ (catalog 4333760F), Pgf(catalog Mm00435613_m1), Flt1 (catalog Mm01210866_ m1). SYBR Green primers: $18 S$ (F: 5'-ACCTTTCGATGGTAGTCGCCG-3', R: 5'-CCTTGGATGTGGTAGCCGTTT-3'), Avp (F: 5'-GCCTACTGGCCTTCTCCTC-3', R: 5'-GGCAGGTAGTTCTCCTCCT-3'), Avprla (F: 5'-GTGCAGAGCAAGCGGGTGTG-3', R: 5'-CGAGTCCTTCCACATACCCGT-3'), Avpr1b (F: 5'-CCAAGATCCGAACAGTGAAGAT-3'， R: 5'-GCTGTTGAAGCCCATGTAGA-3'), Avpr2 (F: 5'-GGCCAAGACTGTGAGGATGA-3'， R: 5'-ACACGCTGCTGCTGAAAGAT-3'), Oxtr (F: 5'-CTCTACTCCAAGGCCAAGAT-3', R: 5'-GTCTGCCCTTCAGGTAGC-3'), Cul5 (F: 5'-GTTTCAGCTCGCTGTATTGTTT-3', R: 5'-TGTGCTCTATTAGCCACTCTATTT-3'), Hk2 (F: 5'-CTGGGTTTCACCTTCTCGTT-3', R: 5'-GATCAGATCCACCACATCTCTG-3'), Ddit4 (F: 5'-TCCGCAATCTTCGCTGAC-3', R: 5'-AGGAAGAGGAGGACGAGAAA-3'), Hiflb (F: 5'-TAGGTCCGACAGCCAATTTATC-3', R: 5'-TGGACAGAAACCTGGGAATG-3'). Gene expression was analyzed using the Livak method (97).

Protein levels. Total protein lysate of placentas was generated by homogenization of tissues in buffer containing $5 \mathrm{M} \mathrm{NaCl}, 1 \mathrm{M}$ Tris, 0.5 M EDTA, NP-40, protease inhibitor (Roche), and phosphatase inhibitor (Roche). A commercially available bicinchoninic acid (BCA) protein assay kit (Thermo Fisher Scientific, 23225) was utilized per manufacturer's protocol to assess total protein concentration. Commercially available ELISAs were used to detect PGF (Thermo Fisher Scientific, catalog EMPGF) and total FLT1 protein (R\&D Systems, catalog DVR100C). 
RNA-Seq. RNA from placentas of pregnant GD 12.5 mice were isolated using a mirVana RNA isolation kit per manufacturer's instructions. Transcriptome profiling using RNA-Seq was performed by the University of Iowa Genomics Division according to manufacturer's recommended protocols. Briefly, 500 ng total RNA was fragmented, converted to cDNA, and ligated to sequencing adaptors containing indexes using the Illumina TruSeq stranded mRNA sample preparation kit (catalog RS-122-2101). The molar concentrations of the indexed libraries were measured using the 2100 Agilent Bioanalyzer and combined equally into pools for sequencing. The concentration of the pools were measured using the Illumina Library Quantification Kit (KAPA Biosystems) and sequenced on the Illumina HiSeq 4000 genome sequencer using a 75-bp paired-end SBS chemistry.

Transcriptomic data analysis. Following RNA-Seq, reads were pseudoaligned to the mouse transcriptome (GRCm38/mm10, University of California, Santa Cruz [UCSC] Genome Browser) and transcripts were quantified using Kallisto v0.43.1 (98). Transcripts were then mapped to their corresponding genes by querying the UCSC database. The gene-level RNA-Seq counts were used to determine DEGs using the open source R/BioConductor software (http:/ /www.bioconductor.org/) and the DESeq2 package (99). An FDR threshold of $10 \%$ was used to determine if a gene was differentially expressed between the placentas from AVP- and saline-infused pregnancies (AVP vs. saline). The transcript per million (TPM) count for each DEG was transformed into a logarithmic value using the formula $\log _{10}(\mathrm{TPM}+1)$, and these values were used as input to generate a heatmap using Morpheus (Broad Institute, https://software.broadinstitute. org/morpheus/). The DEGs were also used as input for further pathway analyses with IPA. The RNA-Seq data have been deposited in the NCBI Gene Expression Omnibus database (GEO GSE116751).

GSEA. Expression and phenotype files were prepared as described previously (100). Analysis was carried out using GSEA software from the Broad Institute (v3.0). The GRD hypoxia-inducible (GRD_Hypoxia) gene set consisted of 146 genes curated from the following gene sets obtained from Molecular Signature Database V6.0 (http://software.broadinstitute.org/gsea/msigdb): (a) genes downregulated in MCF7 cells incubated with siHIF1A and siHIF2A (systemic name: M6189, 104 genes), (b) genes upregulated in MCF7 cells treated with the hypoxia mimetic DMOG (systemic name: M9197, 130 genes), and (c) genes upregulated in MCF7 cells cultured under hypoxic condition $\left(1 \% \mathrm{O}_{2}\right)$ (systemic name: M7363, 171 genes). A stringent criterion was applied to select only genes that appear at least twice in the aforementioned 3 gene sets and those genes were used to compose the GRD hypoxia-inducible gene set; genes are shown in Supplemental Table 4. The Harris hypoxia gene set (systemic name: M10508, 81 genes) and oxidative stress gene set (systemic name: M15990, 96 genes) were downloaded from MSigDB 6.0.

Statistics. All quantitative data were analyzed using Student's $t$ test or ANOVA followed by Tukey's or Dunnett's tests for multiple comparisons as indicated. All tests were 2-tailed unless otherwise noted. Data are shown as the mean \pm SEM. $P$ values less than 0.05 were considered statistically significant.

Study approval. University of Iowa IACUC approval was obtained before any studies were performed. All studies were carried out in accordance with the 8th Guide for the Care and Use of Laboratory Animals (101).

\section{Author contributions}

JAS, DAS, CDS, KNGC, GLP, MKS, and JLG conceived of the project. JAS, GD, DWL, SMS, KJP, ARN, TEN, SYZ, LNA, JW, HLK, MCN, NAP, KAZ, RMW, NCB, YMU, DAS, MJP, KNGC, MKS, and JLG collected and analyzed data. JAS and JLG drafted the manuscript and figures, and all authors reviewed and approved the final manuscript.

\section{Acknowledgments}

The authors would like to acknowledge the intellectual insights and technical assistance of Allyn L. Mark, Kamal Rahmouni, Frank M. Faraci, Anne E. Kwitek, Eric J. Devor, Charles Warwick, Sarah A. Sapouckey, Mary Boes, and the University of Iowa Medical Scientist Training Program. We would also like to thank the Genomics Division of the Iowa Institute of Human Genetics for performing RNA-Seq, as well as the Comparative Pathology Laboratory and the Department of Pathology for histology and electron microscopy support. Finally, we gratefully acknowledge critical external reviews of our findings and this manuscript by James M. Roberts (Magee-Womens Research Institute, University of Pittsburgh), and Michael J. Soares (University of Kansas Medical Center). This work was supported by grants from the American Heart Association (15SFRN23480000, 15SFRN23730000, 15SFRN23760002, 15SFRN23860007, and 18EIA33890055), NIH (HL134850, HL084207, OD019941, and NS087068), Shelly Bridgewater Dreams Foundation, Swift Family Foundation, University of Iowa 
Hospitals \& Clinics Center for Hypertension Research, and the Roy J. Carver Trust. Students were supported by fellowships from the NIH (GM067795 [to JAS] and AI007260 [to SMS]), the American Heart Association (16PRE30980043 [to JAS], 17PRE33660633 [to KJP], 16POST30960016 [to SMS], and 15UFEL25850040 [to DWL]), the American Physiological Society (UGREF [to DWL] and UGSRF [to TEN and SYZ]), and the Iowa Center for Research by Undergraduates (to DWL, TEN, and SYZ). The Genomics Division of the Iowa Institute of Human Genetics is supported, in part, by the University of Iowa Carver College of Medicine and the Holden Comprehensive Cancer Center (National Cancer Institute of the NIH, P30CA086862).

Address correspondence to: Justin L. Grobe, Department of Pharmacology, 51 Newton Road, 2-307 BSB, Iowa City, Iowa 52242, USA. Phone: 319.353.5789; Email: justin-grobe@uiowa.edu. Or to: Mark K. Santillan, Department of Obstetrics and Gynecology, 200 Hawkins Drive, Iowa City, Iowa 52242, USA. Phone: 319.356.3180; Email: mark-santillan@uiowa.edu.

1. Leeman L, Dresang LT, Fontaine P. Hypertensive disorders of pregnancy. Am Fam Physician. 2016;93(2):121-127.

2. Stillman IE, Karumanchi SA. The glomerular injury of preeclampsia. J Am Soc Nephrol. 2007;18(8):2281-2284.

3. Merviel P, Carbillon L, Challier JC, Rabreau M, Beaufils M, Uzan S. Pathophysiology of preeclampsia: links with implantation disorders. Eur J Obstet Gynecol Reprod Biol. 2004;115(2):134-147.

4. Task Force on Hypertension in Pregnancy. Hypertension in Pregnancy. American College of Obstetricians and Gynecologists. https://www.acog.org/Resources-And-Publications/Task-Force-and-Work-Group-Reports/Hypertension-in-Pregnancy. Accessed September 7, 2018.

5. Leavey K, Bainbridge SA, Cox BJ. Large scale aggregate microarray analysis reveals three distinct molecular subclasses of human preeclampsia. PLoS One. 2015;10(2):e0116508.

6. Persson PB. 2003 was a good year for the American Journal of Physiology-Regulatory, Integrative and Comparative Physiology. Am J Physiol Regul Integr Comp Physiol. 2004;286(4):R607.

7. McCarthy FP, Kingdom JC, Kenny LC, Walsh SK. Animal models of preeclampsia; uses and limitations. Placenta. 2011;32(6):413-419.

8. Erlandsson L, et al. Inventory of novel animal models addressing etiology of preeclampsia in the development of new therapeutic/intervention opportunities. Am J Reprod Immunol. 2016;75(3):402-410.

9. Fenske WK, et al. Release and decay kinetics of copeptin vs AVP in response to osmotic alterations in healthy volunteers. J Clin Endocrinol Metab. 2018;103(2):505-513.

10. Santillan MK, et al. Vasopressin in preeclampsia: a novel very early human pregnancy biomarker and clinically relevant mouse model. Hypertension. 2014;64(4):852-859.

11. Tuten A, et al. Maternal serum copeptin concentrations in early- and late-onset pre-eclampsia. Taiwan J Obstet Gynecol. 2015;54(4):350-354.

12. Yeung EH, et al. Increased levels of copeptin before clinical diagnosis of preeclampsia. Hypertension. 2014;64(6):1362-1367.

13. Zulfikaroglu E, et al. Circulating levels of copeptin, a novel biomarker in pre-eclampsia. J Obstet Gynaecol Res. 2011;37(9):1198-1202.

14. Foda AA, Abdel Aal IA. Maternal and neonatal copeptin levels at cesarean section and vaginal delivery. Eur J Obstet Gynecol Reprod Biol. 2012;165(2):215-218.

15. Sugulle M, Herse F, Seiler M, Dechend R, Staff AC. Cardiovascular risk markers in pregnancies complicated by diabetes mellitus or preeclampsia. Pregnancy Hypertens. 2012;2(4):403-410.

16. Yeşil A, Kanawati A, Helvacioğlu Ç, Kaya C, Özgün ÇG, Cengiz H. Identification of patients at risk for preeclampsia with the use of uterine artery Doppler velocimetry and copeptin. J Matern Fetal Neonatal Med. 2017;30(22):2763-2768.

17. Akinlade KS, Adediji IO, Rahamon SK, Fawole AO, Tongo OO. Serum copeptin and pregnancy outcome in preeclampsia. Niger Med J. 2015;56(5):362-368.

18. Roberts EM, Newson MJ, Pope GR, Landgraf R, Lolait SJ, O'Carroll AM. Abnormal fluid homeostasis in apelin receptor knockout mice. J Endocrinol. 2009;202(3):453-462.

19. Lindheimer MD, Barron WM, Davison JM. Osmoregulation of thirst and vasopressin release in pregnancy. Am J Physiol. 1989;257(2 Pt 2):F159-F169.

20. Lindheimer MD, Davison JM. Osmoregulation, the secretion of arginine vasopressin and its metabolism during pregnancy. Eur J Endocrinol. 1995;132(2):133-143.

21. Kane SC, Dennis AT. Doppler assessment of uterine blood flow in pre-eclampsia: A review. Hypertens Pregnancy. 2015;34(4):400-421.

22. Chesley LC. Vascular reactivity in normal and toxemic pregnancy. Clin Obstet Gynecol. 1966;9(4):871-881.

23. Anderson CM, Lopez F, Zhang HY, Pavlish K, Benoit JN. Reduced uteroplacental perfusion alters uterine arcuate artery function in the pregnant Sprague-Dawley rat. Biol Reprod. 2005;72(3):762-766.

24. Crews JK, Herrington JN, Granger JP, Khalil RA. Decreased endothelium-dependent vascular relaxation during reduction of uterine perfusion pressure in pregnant rat. Hypertension. 2000;35(1 Pt 2):367-372.

25. Sholook MM, Gilbert JS, Sedeek MH, Huang M, Hester RL, Granger JP. Systemic hemodynamic and regional blood flow changes in response to chronic reductions in uterine perfusion pressure in pregnant rats. Am J Physiol Heart Circ Physiol. 2007;293(4):H2080-H2084.

26. Fushima T, et al. Reduced uterine perfusion pressure (RUPP) model of preeclampsia in mice. PLoS One. 2016;11(5):e0155426.

27. Dokras A, et al. Severe feto-placental abnormalities precede the onset of hypertension and proteinuria in a mouse model of 
preeclampsia. Biol Reprod. 2006;75(6):899-907.

28. De Paco C, et al. Umbilical artery Doppler at 19 to 22 weeks of gestation in the prediction of adverse pregnancy outcomes Prenat Diagn. 2014;34(7):711-715.

29. Bolz N, et al. Value of Doppler sonography near term: can umbilical and uterine artery indices in low-risk pregnancies predict perinatal outcome? J Perinat Med. 2013;41(2):165-170.

30. Lindqvist PG, Procházka M, Laurini R, Maršál K. Umbilical artery Doppler in relation to placental pathology and FV Leiden in pregnant women and their offspring. J Matern Fetal Neonatal Med. 2013;26(14):1394-1398.

31. Maruotti GM, et al. Are there any relationships between umbilical artery pulsatility index and macrosomia in fetuses of type I diabetic mothers? J Matern Fetal Neonatal Med. 2014;27(17):1776-1781.

32. Lewinsky RM, Degani S, Eibschitz I, Sharf M. Flow-velocity profiles of the fetal aorta and umbilical artery in pregnancies complicated by pregnancy-induced hypertension and fetal growth retardation. Obstet Gynecol. 1991;78(4):631-636.

33. Ursem NT, Clark EB, Keller BB, Hop WC, Wladimiroff JW. Do heart rate and velocity variability derived from umbilical artery velocity waveforms change prior to clinical pregnancy-induced hypertension? Ultrasound Obstet Gynecol. 1999;14(4):244-249.

34. Bhide A, et al. ISUOG practice guidelines: use of Doppler ultrasonography in obstetrics. Ultrasound Obstet Gynecol. 2013;41(2):233-239.

35. Detti L, Akiyama M, Mari G. Doppler blood flow in obstetrics. Curr Opin Obstet Gynecol. 2002;14(6):587-593.

36. Hill MA. Embryology: Carnegie Stage Comparison. UNSW Embryology. https://embryology.med.unsw.edu.au/embryology/ index.php/Carnegie_Stage_Comparison. Updated May 22, 2018. Accessed September 7, 2018.

37. Lyall F, Robson SC, Bulmer JN. Spiral artery remodeling and trophoblast invasion in preeclampsia and fetal growth restriction: relationship to clinical outcome. Hypertension. 2013;62(6):1046-1054.

38. Brosens IA, Robertson WB, Dixon HG. The role of the spiral arteries in the pathogenesis of preeclampsia. Obstet Gynecol Annu. 1972;1:177-191.

39. Brosens I, Robertson WB, Dixon HG. The physiological response of the vessels of the placental bed to normal pregnancy. J Pathol Bacteriol. 1967;93(2):569-579.

40. Ball E, Bulmer JN, Ayis S, Lyall F, Robson SC. Late sporadic miscarriage is associated with abnormalities in spiral artery transformation and trophoblast invasion. J Pathol. 2006;208(4):535-542.

41. Livingston JC, Chin R, Haddad B, McKinney ET, Ahokas R, Sibai BM. Reductions of vascular endothelial growth factor and placental growth factor concentrations in severe preeclampsia. Am J Obstet Gynecol. 2000;183(6):1554-1557.

42. Taylor RN, Grimwood J, Taylor RS, McMaster MT, Fisher SJ, North RA. Longitudinal serum concentrations of placental growth factor: evidence for abnormal placental angiogenesis in pathologic pregnancies. Am J Obstet Gynecol. 2003;188(1):177-182.

43. Tidwell SC, Ho HN, Chiu WH, Torry RJ, Torry DS. Low maternal serum levels of placenta growth factor as an antecedent of clinical preeclampsia. Am J Obstet Gynecol. 2001;184(6):1267-1272.

44. Maynard SE, et al. Excess placental soluble fms-like tyrosine kinase 1 (sFlt1) may contribute to endothelial dysfunction, hypertension, and proteinuria in preeclampsia. J Clin Invest. 2003;111(5):649-658.

45. Spradley FT, et al. Placental growth factor administration abolishes placental ischemia-induced hypertension. Hypertension. 2016;67(4):740-747

46. Makris A, et al. Placental growth factor reduces blood pressure in a uteroplacental ischemia model of preeclampsia in nonhuman primates. Hypertension. 2016;67(6):1263-1272.

47. Gigante B, Morlino G, Gentile MT, Persico MG, De Falco S. Plgf-/-eNos-/- mice show defective angiogenesis associated with increased oxidative stress in response to tissue ischemia. FASEB J. 2006;20(7):970-972.

48. Roberts JM, Hubel CA. The two stage model of preeclampsia: variations on the theme. Placenta. 2009;30 Suppl A:S32-S37.

49. Chakraborty D, et al. HIF-KDM3A-MMP12 regulatory circuit ensures trophoblast plasticity and placental adaptations to hypoxia. Proc Natl Acad Sci USA. 2016;113(46):E7212-E7221.

50. Rosario GX, Konno T, Soares MJ. Maternal hypoxia activates endovascular trophoblast cell invasion. Dev Biol. 2008;314(2):362-375.

51. Soares MJ, Iqbal K, Kozai K. Hypoxia and placental development. Birth Defects Res. 2017;109(17):1309-1329.

52. Harris AL. Hypoxia--a key regulatory factor in tumour growth. Nat Rev Cancer. 2002;2(1):38-47.

53. Leavey K, Benton SJ, Grynspan D, Kingdom JC, Bainbridge SA, Cox BJ. Unsupervised placental gene expression profiling identifies clinically relevant subclasses of human preeclampsia. Hypertension. 2016;68(1):137-147.

54. Dobierzewska A, et al. NFAT5 is up-regulated by hypoxia: possible implications in preeclampsia and intrauterine growth restriction. Biol Reprod. 2015;93(1):14.

55. Hamai Y, et al. Evidence for an elevation in serum interleukin-2 and tumor necrosis factor-alpha levels before the clinical manifestations of preeclampsia. Am J Reprod Immunol. 1997;38(2):89-93.

56. Haché S, et al. Alteration of calcium homeostasis in primary preeclamptic syncytiotrophoblasts: effect on calcium exchange in placenta. J Cell Mol Med. 2011;15(3):654-667.

57. Chen $\mathrm{Q}$, et al. Pre-treatment with calcium prevents endothelial cell activation induced by multiple activators, necrotic trophoblastic debris or IL-6 or preeclamptic sera: possible relevance to the pathogenesis of preeclampsia. Placenta. 2013;34(12):1196-1201.

58. Sankaralingam S, Xu H, Jiang Y, Sawamura T, Davidge ST. Evidence for increased methylglyoxal in the vasculature of women with preeclampsia: role in upregulation of LOX-1 and arginase. Hypertension. 2009;54(4):897-904.

59. Yu Y, et al. Reduced soluble receptor for advanced glycation end-products (sRAGE) scavenger capacity precedes pre-eclampsia in Type 1 diabetes. BJOG. 2012;119(12):1512-1520.

60. Tadesse S, et al. Dynamics of base excision repair at the maternal-fetal interface in pregnancies complicated by preeclampsia. Reprod Sci. 2017;24(6):856-864.

61. Tadesse S, et al. In vivo and in vitro evidence for placental DNA damage in preeclampsia. PLoS One. $2014 ; 9(1): e 86791$.

62. Vural P, Değirmencioğlu S, Doğru-Abbasoğlu S, Saral NY, Akgül C, Uysal M. Genetic polymorphisms in DNA repair gene APE1, XRCC1 and XPD and the risk of pre-eclampsia. Eur J Obstet Gynecol Reprod Biol. 2009;146(2):160-164.

63. Moslehi R, Ambroggio X, Nagarajan V, Kumar A, Dzutsev A. Nucleotide excision repair/transcription gene defects in the fetus and impaired TFIIH-mediated function in transcription in placenta leading to preeclampsia. BMC Genomics. 2014;15:373. 
64. Tamura D, et al. High-risk pregnancy and neonatal complications in the DNA repair and transcription disorder trichothiodystrophy: report of 27 affected pregnancies. Prenat Diagn. 2011;31(11):1046-1053.

65. Saadat I, Beyzaei Z, Aghaei F, Kamrani S, Saadat M. Association between polymorphisms in DNA repair genes (XRCC1 and XRCC7) and risk of preeclampsia. Arch Gynecol Obstet. 2012;286(6):1459-1462.

66. Sandoval-Carrillo A, et al. Polymorphisms in DNA repair genes (APEX1, XPD, XRCC1 and XRCC3) and risk of preeclampsia in a Mexican mestizo population. Int J Mol Sci. 2014;15(3):4273-4283.

67. Zhang X, Xu Z, Lin F, Wang F, Ye D, Huang Y. Increased oxidative DNA damage in placenta contributes to cadmium-induced preeclamptic conditions in rat. Biol Trace Elem Res. 2016;170(1):119-127.

68. Ermini L, Post M, Caniggia I. Statins, mevalonate pathway and its intermediate products in placental development and preeclampsia. Curr Mol Pharmacol. 2017;10(2):152-160.

69. Graham CH, et al. Establishment and characterization of first trimester human trophoblast cells with extended lifespan. Exp Cell Res. 1993;206(2):204-211.

70. Reeves WB, Bichet DG, Andreoli TE. Posterior pituitary and water metabolism. In: Wilson JD, Foster DW, Kronenberg HM, Larsen PR, eds. Williams Textbook of Endocrinology 9th Edition. Philadelphia, Pennsylvania, USA: W. B. Saunders; 1998:341-387.

71. Aoyagi T, et al. Alteration of glucose homeostasis in V1a vasopressin receptor-deficient mice. Endocrinology. 2007;148(5):2075-2084.

72. Hiroyama M, et al. Hypermetabolism of fat in V1a vasopressin receptor knockout mice. Mol Endocrinol. 2007;21(1):247-258

73. Hiroyama M, et al. Hyperammonaemia in V1a vasopressin receptor knockout mice caused by the promoted proteolysis and reduced intrahepatic blood volume. J Physiol (Lond). 2007;581(Pt 3):1183-1192.

74. Scroggins SM, et al. Elevated vasopressin in pregnant mice induces T-helper subset alterations consistent with human preeclampsia. Clin Sci. 2018;132(3):419-436.

75. Nawathe A, Govind A. Pregnancy with known syndrome of inappropriate antidiuretic hormone. J Obstet Gynaecol. 2013;33(1):9-13.

76. Zerbe RL, Vinicor F, Robertson GL. Plasma vasopressin in uncontrolled diabetes mellitus. Diabetes. 1979;28(5):503-508

77. Saleem U, et al. Plasma carboxy-terminal provasopressin (copeptin): a novel marker of insulin resistance and metabolic syndrome. J Clin Endocrinol Metab. 2009;94(7):2558-2564.

78. Carmichael CY, Wainford RD. Hypothalamic signaling mechanisms in hypertension. Curr Hypertens Rep. 2015;17(5):39.

79. Koshimizu TA, Nakamura K, Egashira N, Hiroyama M, Nonoguchi H, Tanoue A. Vasopressin V1a and V1b receptors: from molecules to physiological systems. Physiol Rev. 2012;92(4):1813-1864.

80. Nakanishi K, Mattson DL, Gross V, Roman RJ, Cowley AW. Control of renal medullary blood flow by vasopressin V1 and V2 receptors. Am J Physiol. 1995;269(1 Pt 2):R193-R200.

81. Vila JM, et al. Contractile responses of human thyroid arteries to vasopressin. Life Sci. 2013;93(15):525-529.

82. Tal R. The role of hypoxia and hypoxia-inducible factor-1alpha in preeclampsia pathogenesis. Biol Reprod. 2012;87(6):134

83. Redman CW, Sargent IL, Staff AC. IFPA Senior Award Lecture: making sense of pre-eclampsia - two placental causes of preeclampsia? Placenta. 2014;35 Supp1:S20-S25.

84. Xiong Y, Liebermann DA, Holtzman EJ, Jeronis S, Hoffman B, Geifman-Holtzman O. Preeclampsia-associated stresses activate Gadd45a signaling and sFlt-1 in placental explants. J Cell Physiol. 2013;228(2):362-370.

85. Soothill PW, Nicolaides KH, Rodeck CH, Campbell S. Effect of gestational age on fetal and intervillous blood gas and acid-base values in human pregnancy. Fetal Ther. 1986;1(4):168-175.

86. Qian D, et al. Normoxic induction of the hypoxic-inducible factor-1 alpha by interleukin-1 beta involves the extracellular signalregulated kinase 1/2 pathway in normal human cytotrophoblast cells. Biol Reprod. 2004;70(6):1822-1827.

87. Claflin KE, et al. Angiotensin AT1A receptors on leptin receptor-expressing cells control resting metabolism. J Clin Invest. 2017;127(4):1414-1424.

88. Littlejohn NK, et al. Suppression of resting metabolism by the angiotensin AT2 receptor. Cell Rep. 2016;16(6):1548-1560.

89. Santillan MK, et al. Pregnant mice lacking indoleamine 2,3-dioxygenase exhibit preeclampsia phenotypes. Physiol Rep. 2015;3(1):e12257.

90. Littlejohn NK, et al. Hypertension in mice with transgenic activation of the brain renin-angiotensin system is vasopressin dependent. Am J Physiol Regul Integr Comp Physiol. 2013;304(10):R818-R828.

91. Grobe JL, et al. Angiotensinergic signaling in the brain mediates metabolic effects of deoxycorticosterone (DOCA)-salt in C57 mice. Hypertension. 2011;57(3):600-607.

92. Agbor LN, et al. Cullin-3 mutation causes arterial stiffness and hypertension through a vascular smooth muscle mechanism. JCI Insight. 2016;1(19):e91015.

93. Hartley CJ, Taffet GE, Reddy AK, Entman ML, Michael LH. Noninvasive cardiovascular phenotyping in mice. ILAR J. 2002;43(3):147-158

94. Monk JM, Leonard S, McBey BA, Croy BA. Induction of murine spiral artery modification by recombinant human interferongamma. Placenta. 2005;26(10):835-838.

95. Chakraborty C, Gleeson LM, McKinnon T, Lala PK. Regulation of human trophoblast migration and invasiveness. Can J Physiol Pharmacol. 2002;80(2):116-124.

96. Shutov LP, et al. The complement system component C5a produces thermal hyperalgesia via macrophage-to-nociceptor signaling that requires NGF and TRPV1. J Neurosci. 2016;36(18):5055-5070.

97. Livak KJ, Schmittgen TD. Analysis of relative gene expression data using real-time quantitative PCR and the 2(-delta delta C(T)) Method. Methods. 2001;25(4):402-408.

98. Bray NL, Pimentel H, Melsted P, Pachter L. Near-optimal probabilistic RNA-seq quantification. Nat Biotechnol. 2016;34(5):525-527.

99. Love MI, Huber W, Anders S. Moderated estimation of fold change and dispersion for RNA-seq data with DESeq2. Genome Biol. 2014;15(12):550.

100. Subramanian A, et al. Gene set enrichment analysis: a knowledge-based approach for interpreting genome-wide expression profiles. Proc Natl Acad Sci USA. 2005;102(43):15545-15550.

101. National Research Council Committee for the Update of the Guide for the Care Use of Laboratory Animals. Guide for the Care Use of Laboratory Animals. Washington,DC: National Academies Press (US);National Academy of Sciences;2011. 
102. Tong J, Zhao W, Lv H, Li WP, Chen ZJ, Zhang C. Transcriptomic profiling in human decidua of severe preeclampsia detected by RNA sequencing. J Cell Biochem. 2018;119(1):607-615.

103. Enquobahrie DA, Meller M, Rice K, Psaty BM, Siscovick DS, Williams MA. Differential placental gene expression in preeclampsia. Am J Obstet Gynecol. 2008;199(5):566.e1-566.11.

104. Sandgren JA, et al. Angiotensin AT1A receptors expressed in vasopressin-producing cells of the supraoptic nucleus contribute to osmotic control of vasopressin. Am J Physiol Regul Integr Comp Physiol. 2018;314(6):R770-R780.

105. Lopez-Hernandez Y, et al. Nested case-control study reveals increased levels of urinary proteins from human kidney toxicity panels in women predicted to develop preeclampsia. Int Urol Nephrol. 2016;48(12):2051-2059.

106. Hsu TY, et al. Proteomic profiling reveals $\alpha 1$-antitrypsin, $\alpha 1$-microglobulin, and clusterin as preeclampsia-related serum proteins in pregnant women. Taiwan J Obstet Gynecol. 2015;54(5):499-504.

107. Oztas E, et al. Increased levels of serum clusterin is associated with intrauterine growth restriction and adverse pregnancy outcomes in preeclampsia. J Perinat Med. 2016;44(3):269-275.

108. Blumenstein M, McCowan LM, Wu S, Cooper GJ, North RA, SCOPE consortium. Plasma clusterin increased prior to small for gestational age (SGA) associated with preeclampsia and decreased prior to SGA in normotensive pregnancies. Reprod Sci. 2012;19(6):650-657.

109. Shin JK, et al. Expression of clusterin in normal and preeclamptic placentas. J Obstet Gynaecol Res. 2008;34(4):473-479.

110. Watanabe $\mathrm{H}$, et al. Proteome analysis reveals elevated serum levels of clusterin in patients with preeclampsia. Proteomics. 2004;4(2):537-543.

111. Wen Q, et al. Peptidomic identification of serum peptides diagnosing preeclampsia. PLoS One. 2013;8(6):e65571.

112. Kaartokallio T, et al. Gene expression profiling of pre-eclamptic placentae by RNA sequencing. Sci Rep. 2015;5:14107.

113. Stallone G, et al. Semaphorin $3 \mathrm{~F}$ expression is reduced in pregnancy complicated by preeclampsia. An observational clinical study. PLoS One. 2017;12(3):e0174400.

114. Marino GI, Kotsias BA. Expression of the epithelial sodium channel sensitive to amiloride (ENaC) in normal and preeclamptic human placenta. Placenta. 2013;34(2):197-200.

115. Lee GT, Price MD, Mejia CA, Galan HL, Arroyo JA. Increased trophoblast expression of NFAT5/TonEBP in pre-eclamptic placentas and hyperosmolar-treated BeWo cells. Eur J Obstet Gynecol Reprod Biol. 2014;183:37-43.

116. Park JK, et al. Increased NFAT5 expression stimulates transcription of Hsp70 in preeclamptic placentas. Placenta. 2014;35(2):109-116 